\title{
Comparative design of E-glass and flax structures based on reliability
}

\author{
J.M.F.A. Blanchard and A.J. Sobey
}

\begin{abstract}
Flax fibres are often documented as having equivalent properties to E-glass ones. Based on these comparisons they have been proposed as a suitable replacement for E-glass in structural applications. However, some recent experimental studies demonstrate that flax behaves differently to conventional composites at the structural scale, which indicates that the capabilities of flax need to be better understood at this scale. This paper therefore uses reliability analysis to generate flax structures with an equivalent safety to those in E-glass, accounting for the change in behaviour. An extensive literature review of flax laminate mechanical properties is performed to define their range and variations. These values are used to simulate probabilities of failure which demonstrate that flax structure needs to be 2.4 times heavier than the E-glass structures to have an equivalent safety. It concludes that flax fibres might be used in some applications but cannot replace E-glass in volume constrained structures.
\end{abstract}

Keywords: Natural fibres; strength; analytical modelling; numerical analysis; statistical properties; mechanical properties

\section{Potential for flax structures}

Flax materials are viewed as a sustainable alternative to standard composites with a number of advantages. They exhibit low densities, good damping and vibration absorption in addition to their ecological benefits. Across the research literature flax fibre reinforced composites are proposed as a potential replacement to E-glass for structural applications. Their fibre properties are well studied, [1] [2] [3], and often demonstrate specific mechanical properties comparable or superior to E-glass, [4] [5] [6]. This is despite the variability in the fibres caused by their natural origins, where differences in cultivation conditions and processing are often cited as a limitation. Despite being proposed as an inhibitor to structural applications this variability at the fibre scale is shown to be reduced to an acceptable level at the laminate scale, Blanchard et al. [7], Torres et al. [8] and Liang et al. [9]. By extrapolating the performance from the results at the coupon scale, Mehmood and Madsen [10], Bodros et al. [11] and Meredith et al. [12], demonstrate the potential for flax fibres to replace E-glass at the structural scale.

Whilst flax fibre and laminate scale properties are a popular topic, with 765 journal papers published on these topics in the top 4 composite journals in the last 5 years, studies at the structural scale are still limited, with only 4 papers. These studies have found that flax structures change their behaviour when compared to conventional composites, [13] [14] [15] [16]. This creates a requirement for further investigations as extrapolation of material properties from laminate scale does not account for these structural effects. Shah et al. [13] compare flax composites with E-glass composites as a replacement material for a small wind turbine structure. The flax turbine is $10 \%$ lighter than the Eglass structure and passes the structural requirements however the flax structure has a different 
failure mode and larger deflection than the E-glass ones and the effects of these deformations on the efficiency of the blade are not determined; the comparative safety of the blades is also not documented. Blanchard et al. [14] also find a change in behaviour when flax is used in a structure with an increase in stress for flax grillage structures compared to E-glass and carbon equivalents. Bambach [15] experimentally investigates channel sections made of natural fibre composites where it is shown that natural fibre sections can be used in light structural applications because of their predictable compressive behaviour. However, the mechanical properties at the coupon scale are low and no comparison is made with conventional composite materials. This work is extended by optimising the geometry of the channel sections and compared to steel equivalent structures. It is shown that thicker flax specimens, $4.8 \mathrm{~mm}$ compared to $1.15 \mathrm{~mm}$ for steel, are able to meet the criteria for load bearing walls [16], though the safety factors associated with the structures are not compared. The author noted that the natural fibre sections are substantially less stiff than the steel structures and serviceability requirements will need to be considered; which are traditionally the more difficult condition to meet in composite applications.

To further explore the feasibility for flax fibre reinforced structures this paper uses a reliability analysis to determine structures with equivalent safety values made form E-glass and flax. The approach reflects current industry best practice for structural design and is performed on a secondary structure from a marine application. A literature review of flax fibre reinforced epoxy laminate mechanical properties is conducted to gain a better understanding of the currently available material properties and determine a realistic range of mechanical properties. An assessment is made of the structure as if it was made from a flax fibre reinforced epoxy composites and compared to an E-glass equivalent. Material properties are taken from the literature, comparing the structural integrity of the panel across the full range of values found in the literature. The influences of these material properties and manufacturing techniques on the structural properties are then investigated. To perform the analysis, Monte Carlo simulation is combined with an analytical grillage model successfully validated for flax reinforced epoxy composites by Blanchard et al. [14].

\section{Analysis of material properties from the literature}

Due to the range of mechanical properties seen in the academic literature for composites, especially flax fibres, it is important to establish a realistic set of data, to ensure they represent properties likely to be seen in industry. A review is performed of both the available mechanical properties for flax and E-glass fibre reinforced laminate properties, to establish a benchmark reference for the reliability exercise.

\subsection{Data collection method for flax and E-glass laminate mechanical properties.}

A set of criteria is defined to determine which data should be selected for consistency and to objectively remove some academic studies which provide unrealistic properties. The main selection criteria for both materials are the same, with some additional ones specific to flax due to larger quantity of literature exploring techniques to improve the properties which have not proven to be industry ready. For flax composites, a large majority, 73\%, of the papers were published in the last 5 years. For E-glass, the data have a larger spread with $44 \%$ of the papers published in the last five years and oldest reference published in 1981. However, within the limited available literature the 
year of publication has no influence on the properties and is stable with time. The following general rules are followed:

- UD reinforcement is selected for this study to reduce the variability associated with different types of reinforcement and to obtain the highest mechanical properties. However purely unidirectional fabrics do not provide enough data and so fabrics with a minimum of $90 \%$ of the fibres in the longitudinal direction are also included.

- All the laminates have to be reinforced with a similar matrix to isolate the fibre properties from the matrix. Epoxy resin is selected for this exercise as the most data is available while also exhibiting good compatibility with flax and E-glass fibres. Furthermore, the high properties of epoxy resins help flax laminates reach their full potential.

- If different fibre volume fractions are tested in the same study, only the highest volume fraction is selected to represent the highest mechanical properties reachable in industrial applications.

- All the manufacturing techniques are considered except pultrusion, due to the different geometries of the resulting specimens.

- If different numbers of layers or different manufacturing techniques are compared, all data are included to cover a range of manufacturing processes.

- Data presented in graphs for which it is difficult to obtain exact numbers and non-peer reviewed sources are not considered. Non-experimental data are also discarded.

- A large number of studies for flax laminates investigate various fibre treatments to improve the properties of the laminates. The effects of these chemical treatments on the laminate properties are inconsistent: Van de Weyenberg et al. [17], Acera Fernandez et al. [18] and Shah [19]; or costly for industrial applications: Meredith et al. [12], Coroller et al. [20] and Shah [19]. Therefore, data based on the utilisation of chemical treatments such as Alkaline, stearic acid and silane solutions are discarded. Reinforcements subjected to mild treatments: water, cellulose based binder and fibres used as received with possible treatments applied by manufacturers are included as the influence of these treatments on the average properties is negligible.

- Flax reinforcements subjected to heat treatments before manufacturing are included as heat treatments are commonly used and applicable in an industrial context. The influence of heat treatments on the average properties is investigated and statistically negligible.

The full set of data is presented in the data attachment. Initially 60 papers for flax laminate properties and 34 papers for E-glass laminate properties are selected. From the initial selection, 7 papers are discarded for flax and 3 papers for E-glass as the data did not meet the criteria. The final set of data represents up to 273 tested specimens for the flax laminate and 49 data points for E-glass for the most available material property, Young's modulus. However, this is reduced to 3 tested specimens for the compressive strength, the least available material property.

Representative values for the mechanical properties and the coefficients of variation are determined by statistical analysis. All the data meeting the above conditions are collated into a box plot. On each box, the central mark indicates the median, and the bottom and top edges of the box indicate the 25th and 75th percentiles, respectively. The whiskers extend to the most extreme data points not 
considered outliers, and the outliers are plotted individually using the ' + ' symbol. These outliers are then discarded as they are not considered to be representative of the values likely to be seen in industry. The outliers plotted in the graphs are removed for the calculations of the average, minimum and maximum values. However, since most of the specimens are manufactured within a laboratory environment it is likely that they still represent optimistic values compared to what might be seen within the industry. The mean, minimum and maximum values are then calculated to be used in the analysis to represent the range of properties it might be possible for industry to replicate. This is repeated for the coefficient of variation (CoV). In addition to the outlier the coefficient of variations associated with a data point for which the mechanical property is considered as an outlier are also discarded for the coefficient of variation calculations.

\subsection{Flax/epoxy mechanical properties}

The mechanical properties for unidirectional flax/epoxy laminates are presented in Table 1, where ([X1]/[X2]) represents multiple references citing the same value. The longitudinal Young's modulus of flax fibre reinforced UD epoxy composites is well characterised with 33 references and 58 different tests conducted, representing 273 data points. However, not all of the other properties are as well documented with 11 references for the transverse Young's modulus and 4 references for the longitudinal compressive strength. The limited number of references for these properties prevents the definition of a realistic range. The fibre volume fraction is well characterised with 43 references but this large number is influenced by the number of manufacturing techniques available and is discussed further in section 2.4 .

Table 1: Average (Avg), minimum (Min) and maximum (Max) mechanical properties for Flax/epoxy from the literature

\begin{tabular}{|l|l|l|l|c|c|l|l|}
\hline $\begin{array}{l}\text { Material } \\
\text { Properties }\end{array}$ & Avg. & Min & Max & $\begin{array}{l}\text { \# of } \\
\text { data } \\
\text { points }\end{array}$ & $\begin{array}{l}\text { \# of refs. } \\
\text { included }\end{array}$ & Refs. included & $\begin{array}{l}\text { Discarded } \\
\text { Refs. }\end{array}$ \\
\hline $\begin{array}{l}\text { Longitudinal } \\
\text { Young's } \\
\text { modulus } E_{1} \\
(G P a)\end{array}$ & 25.42 & 11.86 & 40.10 & 58 & 33 & $\begin{array}{l}{[8][9][17]} \\
{[20]-[42]} \\
([43] /[44])\end{array}$ & $\begin{array}{l}{[24]^{1}[33]^{2}} \\
{[50]^{3}[51]^{4}} \\
{[52]^{5}[53]^{6}} \\
{[54]^{7}}\end{array}$ \\
\hline $\begin{array}{l}\text { Transverse } \\
\text { Young's } \\
\text { modulus } E_{2} \\
\text { (GPa) }\end{array}$ & 4.20 & 2.70 & 5.58 & 17 & 11 & $\begin{array}{l}{[9][17][21]} \\
{[29][30][34]} \\
{[35][40]} \\
{[47]-[49]}\end{array}$ & {$[18]^{8}$} \\
\hline
\end{tabular}

\footnotetext{
${ }^{1}$ One data point of the study (fibres from bottom location) was discarded by the box plots as a minimum outlier

${ }^{2}$ Specimens made of FUD115 prepreg are discarded as the weft/wrap ratio is $1 / 8$

${ }^{3}$ Fabric described as UD but only $67 \%$ of the fibres in the $0^{\circ}$ direction

${ }^{4}$ Unknown resin

${ }^{5}$ Range of values given for $E_{1}$

${ }^{6}$ Fabric described as UD - ribs $4 / 4$

${ }^{7}$ Specimens fabricated by pultrusion

${ }^{8}$ Fabric described as UD but weft/ wrap ratio is $84 / 16$ wt\%
} 


\begin{tabular}{|c|c|c|c|c|c|c|c|}
\hline $\begin{array}{l}\text { Shear modulus } \\
\mathrm{G}_{12}(\mathrm{GPa})\end{array}$ & 2.01 & 1.86 & 2.19 & 9 & 5 & $\begin{array}{l}\text { [9] [29] [30] } \\
{[35][55]}\end{array}$ & {$[48]^{9}[55]^{10}$} \\
\hline $\begin{array}{l}\text { Poisson's ratio } \\
V_{12}\end{array}$ & 0.36 & 0.34 & 0.37 & 10 & 5 & $\begin{array}{l}\text { [29] [30] [34] } \\
{[35][48]}\end{array}$ & $\begin{array}{l}{[5]^{11}[9]^{11}} \\
{[42]^{11}}\end{array}$ \\
\hline $\begin{array}{l}\text { Longitudinal } \\
\text { tensile strength } \\
\mathrm{Xt}(\mathrm{MPa})\end{array}$ & 255.14 & 113.00 & 408.00 & 55 & 31 & $\begin{array}{l}{[8]([1] /[56])} \\
{[17][20][21]} \\
{[23]-[28][30]} \\
{[32]-[35]} \\
{[37]-[42]} \\
([43] /[44]) \\
{[45]-[49][57]}\end{array}$ & $\begin{array}{l}{[33]^{12}[50]^{13}} \\
{[51]^{14}[53]^{15}} \\
{[54]^{16}}\end{array}$ \\
\hline $\begin{array}{l}\text { Transverse } \\
\text { tensile strength } \\
\mathrm{Y}_{\mathrm{t}}(\mathrm{MPa})\end{array}$ & 24.81 & 4.50 & 36.53 & 16 & 10 & $\begin{array}{l}9][17][21] \\
{[30][34][35]} \\
{[40][47]-[49]}\end{array}$ & {$[18]^{17}$} \\
\hline $\begin{array}{l}\text { Longitudinal } \\
\text { compressive } \\
\text { strength } \mathrm{X}_{\mathrm{c}} \\
(\mathrm{MPa})\end{array}$ & 127.50 & 110.00 & 136.90 & 4 & 4 & $\begin{array}{l}\text { [9] [21] [30] } \\
{[37]}\end{array}$ & {$[54]^{16}$} \\
\hline $\begin{array}{l}\text { Transverse } \\
\text { compressive } \\
\text { strength } \mathrm{Y}_{\mathrm{c}} \\
(\mathrm{MPa})\end{array}$ & 85.31 & 76.00 & 100.00 & 3 & 3 & [9] [21] [30] & $\mathrm{N} / \mathrm{A}$ \\
\hline $\begin{array}{l}\text { Shear strength } \\
\mathrm{S}_{12}(\mathrm{MPa})\end{array}$ & 39.34 & 32.00 & 45.60 & 6 & 4 & $\begin{array}{l}\text { [9] [30] [55] } \\
{[58]}\end{array}$ & {$[48]^{18}$} \\
\hline $\begin{array}{l}\text { Fibre volume } \\
\text { fraction (\%) }\end{array}$ & 43.64 & 19.70 & 65.00 & 69 & 43 & $\begin{array}{l}{[5][8][9][17]} \\
{[20]-[47][56]} \\
{[58]-[67]}\end{array}$ & $\begin{array}{l}{[18]^{17}[33]^{12}} \\
{[48]^{19}[50]^{13}} \\
{[51]^{14}[59]^{16}} \\
{[68]^{20}}\end{array}$ \\
\hline
\end{tabular}

Table 1 shows that the range of mechanical properties is large, especially for the longitudinal Young's modulus where the maximum value is $57 \%$ larger and the minimum value is $53 \%$ lower than the mean. The minimum value of $11.86 \mathrm{GPa}$ seems particularly low especially considering that the specimens were manufactured with compression moulding but it is not considered as an outlier statistically. A large range of data is also seen for the tensile strengths in both directions. The minimum value for the transverse strength is particularly low, $82 \%$ lower than the mean, even though these specimens were cured in an autoclave for which higher properties can be expected. The range for compressive data is smaller and can be attributed to the large influence of the resin on

\footnotetext{
${ }^{9}$ Discarded by the box plot as a minimum outlier

${ }^{10}$ Data from test 11 was discarded by the box plot as a maximum outlier

${ }^{11}$ Discarded by the box plots as maximum outliers

12 Specimens made of FUD115 prepreg are discarded as the weft/wrap ratio is $1 / 8$

${ }^{13}$ Fabric described as UD but only $67 \%$ of the fibres in the $0^{\circ}$ direction

${ }^{14}$ Unknown resin

${ }^{15}$ Fabric described as UD - ribs 4/4

${ }^{16}$ Specimens fabricated by pultrusion

${ }^{17}$ Fabric described as UD but weft/ wrap ratio is 84/16 wt\%

${ }^{18}$ Discarded by the box plot as a minimum outlier

${ }^{19}$ Range of volume fraction

${ }^{20}$ Specimens fabricated by filament winding are discarded
} 
compression properties. For many of the properties there is still not a large enough quantity of points to gain confidence in the values, despite coming from multiple references. The fibre volume fraction varies with a minimum value of $19.7 \%$ and a maximum value of $65 \%$. The substantial variation in fibre volume fraction might be explained by the different manufacturing techniques and the influence of the manufacturing techniques is investigated in more details in section 2.4. The coefficients of variation from the literature for variation in flax / epoxy mechanical properties are presented in Table 2.

Table 2: Average (Avg), minimum (Min) and maximum (Max) coefficients of variation for flax/epoxy laminates from the literature

\begin{tabular}{|c|c|c|c|c|c|c|c|}
\hline $\operatorname{CoV}(\%)$ & Avg. & Min. & Max. & $\begin{array}{c}\text { \# of } \\
\text { data } \\
\text { points }\end{array}$ & $\begin{array}{l}\text { \# of refs. } \\
\text { included }\end{array}$ & $\begin{array}{l}\text { References } \\
\text { included }\end{array}$ & $\begin{array}{l}\text { Discarded } \\
\text { refs. }\end{array}$ \\
\hline $\begin{array}{l}\text { Longitudinal } \\
\text { Young's modulus } \\
\mathrm{E}_{1}\end{array}$ & 6.62 & 1.28 & 16.37 & 55 & 31 & $\begin{array}{l}{[8][9][17]} \\
{[20]-[28][30]} \\
{[32]-[39][41]} \\
{[42]([43] /[44])} \\
{[45]-[49][67]}\end{array}$ & $\begin{array}{l}{[24]^{21-22}} \\
{[33]^{23}[53]^{24}} \\
{[54]^{25}}\end{array}$ \\
\hline $\begin{array}{l}\text { Transverse } \\
\text { Young's modulus } \\
E_{2}\end{array}$ & 5.49 & 2.38 & 8.96 & 12 & 8 & $\begin{array}{l}\text { [9] [17] [21] [30] } \\
{[34][35][47][48]}\end{array}$ & $\begin{array}{l}{[17]^{26}[18]^{27}} \\
{[34]^{28}}\end{array}$ \\
\hline $\begin{array}{l}\text { Shear modulus } \\
G_{12}\end{array}$ & 6.69 & 2.90 & 9.64 & 8 & 4 & [9] [30] [35] [55] & {$[48]^{29}[55]^{30}$} \\
\hline $\begin{array}{l}\text { Poisson's ratio } \\
V_{12}\end{array}$ & 4.41 & 2.70 & 8.33 & 9 & 4 & [30] [34] [35] [48] & {$[9]^{31}[42]^{31}$} \\
\hline $\begin{array}{l}\text { Longitudinal } \\
\text { tensile strength } \\
\text { Xt }\end{array}$ & 6.87 & 0.17 & 14.81 & 50 & 28 & $\begin{array}{l}{[8]([1] /[56])} \\
{[17][20][21]} \\
{[23]-[28][30]} \\
{[32]-[35][37]} \\
{[38][41][42]} \\
([43] /[44]) \\
{[45]-[49]}\end{array}$ & $\begin{array}{l}{[27]^{32}} \\
{[33]^{23}[53]^{24}} \\
{[54]^{25}} \\
{[67]^{33}}\end{array}$ \\
\hline
\end{tabular}

\footnotetext{
${ }^{21}$ One data point of the study (fibres from bottom location) is discarded by the E1 box plot as a minimum outlier and the associated CoV is discarded

${ }^{22}$ One data point of the study (fibres from middle location) is discarded by the CoV box plot as a maximum outlier

${ }^{23}$ Specimens made of FUD115 prepreg are discarded as the weft/wrap ratio is $1 / 8$

${ }^{24}$ Fabric described as UD - ribs 4/4

${ }^{25}$ Specimens fabricated by pultrusion

${ }^{26}$ Data described as "Film Stacking" is discarded by the box plot as maximum outlier

${ }^{27}$ Fabric described as UD but weft/ wrap ratio is $84 / 16 \mathrm{wt} \%$

${ }^{28}$ Data described as "DRY MTT2" is discarded by the box plot as a maximum outlier

${ }^{29}$ The data for $\mathrm{G}_{12}$ is discarded by the box plot as a minimum outlier and the associated CoV is discarded

${ }^{30}$ One data for $\mathrm{G}_{12}$ (test 11 ) is discarded by the box plot as a maximum outlier and the associated CoV is discarded

31 The data for $\mathrm{v}_{12}$ is discarded by the box plot as a maximum outlier and the associated CoV is discarded

32 Data described as "bottom of the stem $(\mathrm{h}=12.5 \mathrm{~cm})$ " is discarded by the box plot as a maximum outlier

${ }^{33}$ Discarded by the box plot as a maximum outlier
} 


\begin{tabular}{|l|c|c|c|c|c|l|l|}
\hline $\begin{array}{l}\text { Transverse } \\
\text { tensile strength } \\
\mathbf{Y}_{\mathbf{t}}\end{array}$ & 3.87 & 1.08 & 10.00 & 14 & 8 & $\begin{array}{l}{[9][17][21][30]} \\
{[34][35][48][49]}\end{array}$ & {$[18]^{34}[47]^{35}$} \\
\hline $\begin{array}{l}\text { Longitudinal } \\
\text { compressive } \\
\text { strength } \mathbf{X}_{\mathbf{c}}\end{array}$ & 3.16 & 1.47 & 4.02 & 3 & 3 & {$[9][30][37]$} & {$[21]^{36}[54]^{37}$} \\
\hline $\begin{array}{l}\text { Transverse } \\
\text { compressive } \\
\text { strength } \mathbf{Y}_{\mathbf{c}}\end{array}$ & 7.68 & 4.00 & 12.45 & 3 & 3 & {$[9][21][30]$} & N/A \\
\hline $\begin{array}{l}\text { Shear strength } \\
\mathbf{S}_{12}\end{array}$ & 5.04 & 2.99 & 8.31 & 6 & 4 & {$[9][30][55][58]$} & {$[2]^{38}$} \\
\hline
\end{tabular}

The mean values for the coefficient of variation for the different properties are between $3.16 \%$ and $7.68 \%$ and the maximum coefficient of variation reported is $16.37 \%$ for the longitudinal Young's modulus. The minimum values reported are low, especially the minimum value for flax tensile strength variation of $0.17 \%$ and appears to be unrealistically low. These specimens are manufactured with prepreg and autoclave curing, which is an expensive technique for low cost structures, and only three specimens are tested. The influence of the number of specimens tested on the variations is difficult to determine but for all of the minimum and maximum values reported the number of specimens is alternatively 3, 5 or not stated and is an indicator that more experiments are required to determine an accurate range of coefficients of variation for future analysis.

\subsection{E-glass/epoxy mechanical properties}

The unidirectional E-glass/epoxy mechanical properties are presented in Table 3. The number of references for E-glass laminates is limited with 17 data points for the longitudinal Young's modulus which is the most studied mechanical property compared to 55 data points for flax laminates. Though the lowest number of data points is higher, with 6 points for the transverse compressive and shear strengths.

Table 3: Average (Avg), minimum (Min) and maximum (Max) mechanical properties for E-glass/epoxy from the literature

\begin{tabular}{|c|c|c|c|c|c|c|c|}
\hline $\begin{array}{l}\text { Material } \\
\text { Properties }\end{array}$ & Avg. & Min. & Max. & $\begin{array}{c}\text { \# of } \\
\text { data } \\
\text { points }\end{array}$ & $\begin{array}{l}\text { \# of refs. } \\
\text { included }\end{array}$ & $\begin{array}{c}\text { References } \\
\text { included }\end{array}$ & $\begin{array}{l}\text { Discarded } \\
\text { refs. }\end{array}$ \\
\hline $\begin{array}{l}\text { Longitudinal } \\
\text { Young's } \\
\text { modulus }\left(E_{1}\right) \\
\text { GPa }\end{array}$ & 40.97 & 31.00 & 53.48 & 17 & 19 & $\begin{array}{l}{[20][38][43][45]} \\
{[69][70]} \\
([71] /[72]) \\
([73] /[74] /[75])\end{array}$ & $\begin{array}{l}{[84]^{39}} \\
{[85]^{40}} \\
{[86]^{35}} \\
{[87]^{41}}\end{array}$ \\
\hline
\end{tabular}

\footnotetext{
${ }^{34}$ Fabric described as UD but weft/ wrap ratio is $84 / 16$ wt\%

${ }^{35}$ Discarded by the box plot as a maximum outlier

${ }^{36}$ Coefficient of variation stated as $0 \%$

37 Specimens fabricated by pultrusion

${ }^{38}$ The data for $S_{12}$ is discarded by the box plot as a minimum outlier and the associated CoV is discarded

${ }^{39}$ Reference discarded because the resin is unknown

${ }^{40}$ Reference discarded because the experiment is unknown

${ }^{41}$ Reference is discarded because the data are FEA inputs rather than experimental data
} 


\begin{tabular}{|c|c|c|c|c|c|c|c|}
\hline & & & & & & $\begin{array}{l}{[76]([77] /[78])} \\
{[79][80]} \\
([81] /[82])[83]\end{array}$ & \\
\hline $\begin{array}{l}\text { Transverse } \\
\text { Young's } \\
\text { modulus }\left(E_{2}\right) \\
\text { GPa }\end{array}$ & 12.31 & 9.03 & 17.70 & 11 & 13 & $\begin{array}{l}{[70]([71] /[72])} \\
([73] /[75]) \\
([77] /[78])[79] \\
{[80]([81] /[82])} \\
{[83][88]}\end{array}$ & $\begin{array}{l}{[84]^{42}} \\
{[85]^{43}} \\
{[87]^{44}}\end{array}$ \\
\hline $\begin{array}{l}\text { Shear } \\
\text { modulus } \\
\left(G_{12}\right) \mathrm{GPa}\end{array}$ & 5.04 & 3.19 & 6.00 & 9 & 12 & $\begin{array}{l}{[70]([71] /[72])} \\
([73] /[75]) \\
([77] /[78])[79] \\
{[80]([81] /[82])} \\
{[83]}\end{array}$ & $\begin{array}{l}{[84]^{42}} \\
{[85]^{43}} \\
{[87]^{44}}\end{array}$ \\
\hline $\begin{array}{l}\text { Poisson's } \\
\text { ration }\left(v_{12}\right)\end{array}$ & 0.289 & 0.250 & 0.326 & 9 & 12 & $\begin{array}{l}{[70]([71] /[72])} \\
([73] /[75])[76] \\
([77] /[78])[79] \\
{[80]([81] /[82])}\end{array}$ & $\begin{array}{l}{[84]^{42}} \\
{[85]^{43}} \\
{[87]^{44}}\end{array}$ \\
\hline $\begin{array}{l}\text { Longitudinal } \\
\text { tensile } \\
\text { strength }\left(X_{t}\right) \\
\mathrm{MPa}\end{array}$ & 1014.31 & 514.20 & 1280.00 & 16 & 18 & $\begin{array}{l}{[20][38][43][45]} \\
{[3][69]} \\
([71] /[72]) \\
([73] /[74] /[75]) \\
{[76]([77] /[78])} \\
{[80]([81] /[82])} \\
{[86][89]}\end{array}$ & $\begin{array}{l}{[84]^{42}} \\
{[85]^{43}} \\
{[87]^{44}}\end{array}$ \\
\hline $\begin{array}{l}\text { Transverse } \\
\text { tensile } \\
\text { strength }\left(Y_{t}\right) \\
\mathrm{MPa}\end{array}$ & 46.61 & 35.00 & 59.00 & 9 & 11 & $\begin{array}{l}([71] /[72]) \\
([73] /[75]) \\
([77] /[78])[80] \\
([81] /[82])[88] \\
{[89]}\end{array}$ & $\begin{array}{l}{[84]^{42}} \\
{[85]^{43}} \\
{[87]^{44}}\end{array}$ \\
\hline $\begin{array}{l}\text { Longitudinal } \\
\text { compressive } \\
\text { strength }\left(X_{c}\right) \\
\mathrm{MPa}\end{array}$ & 635.29 & 487.00 & 800.00 & 7 & 8 & $\begin{array}{l}([73] /[75])[76] \\
([77] /[78])[80] \\
{[81][89]}\end{array}$ & $\begin{array}{l}{[84]^{42}} \\
{[85]^{43}} \\
{[87]^{44}}\end{array}$ \\
\hline $\begin{array}{l}\text { Transverse } \\
\text { compressive } \\
\text { strength }\left(Y_{c}\right) \\
\mathrm{MPa}\end{array}$ & 128.82 & 114.00 & 145.00 & 6 & 7 & $\begin{array}{l}([73] /[75]) \\
([77] /[78])[80] \\
{[81][89]}\end{array}$ & $\begin{array}{l}{[84]^{42}} \\
{[85]^{43}} \\
{[87]^{44}}\end{array}$ \\
\hline $\begin{array}{l}\text { Shear } \\
\text { strength }\left(S_{12}\right) \\
\mathrm{MPa}\end{array}$ & 67.09 & 49.51 & 98.00 & 6 & 7 & $\begin{array}{l}{[58]([71] /[72])} \\
([77] /[78])[80] \\
{[89]}\end{array}$ & $\begin{array}{l}{[84]^{42}} \\
{[85]^{43}} \\
{[87]^{44}}\end{array}$ \\
\hline $\begin{array}{l}\text { Fibre volume } \\
\text { fraction } \\
\left(V_{f}\right) \%\end{array}$ & 54.42 & 40 & 66.4000 & 21 & 20 & $\begin{array}{l}{[20][38][43][45]} \\
{[58][63][69][73]} \\
{[74][77][78][80]} \\
{[83][88][90]-[95]}\end{array}$ & {$[96]^{45}$} \\
\hline
\end{tabular}

\footnotetext{
${ }^{42}$ Reference discarded because the resin is unknown

${ }^{43}$ Reference discarded because the experiment is unknown

${ }^{44}$ Reference is discarded because the data are FEA inputs rather than experimental data

${ }^{45}$ Data discarded by the box plot as a minimum outlier
} 
The mechanical properties of the E-glass laminates are higher than the properties of the flax laminates, with a smaller range of mechanical properties seen in the literature. The longitudinal Young's modulus has a minimum value $24 \%$ lower and a maximum value $31 \%$ higher than the mean. However, the longitudinal tensile strength has a larger range with the minimum value $49 \%$ lower and a maximum value $26 \%$ higher than the mean. The minimum value of $514 \mathrm{MPa}$ for the longitudinal tensile strength is obtained with specimens manufactured via resin transfer moulding and a targeted fibre volume fraction of $40 \%$ which is low for E-glass. The values for the fibre volume fraction are consistent with a minimum value of $40 \%$ and a maximum value of $66.4 \%$ even though the specimens are manufactured with different manufacturing techniques. Representative coefficients of variation for the E-glass mechanical properties are presented in Table 4. For E-glass/epoxy laminates, only one reference is found for the coefficient of variation of the shear strength, longitudinal and transverse compressive strengths. Therefore the lowest and highest variation from the strength values found for the tensile strengths are used as representative.

Table 4: Average (Avg), minimum (Min) and maximum (Max) coefficients of variation for E-glass/epoxy laminate mechanical properties from the literature

\begin{tabular}{|c|c|c|c|c|c|c|c|}
\hline $\operatorname{CoV}(\%)$ & Avg. & Min. & Max. & $\begin{array}{l}\text { \# of } \\
\text { data } \\
\text { points }\end{array}$ & $\begin{array}{l}\text { \# of refs. } \\
\text { included }\end{array}$ & $\begin{array}{l}\text { Refs. } \\
\text { included }\end{array}$ & $\begin{array}{l}\text { Discarded } \\
\text { refs. }\end{array}$ \\
\hline $\begin{array}{l}\text { Longitudinal } \\
\text { Young's } \\
\left.\text { modulus ( } E_{1}\right)\end{array}$ & 4.87 & 2.92 & 6.78 & 6 & 7 & $\begin{array}{l}{[20][38]} \\
{[43][45]} \\
([71] /[72]) \\
{[83]}\end{array}$ & $\begin{array}{l}{[86]^{46}} \\
{[81]^{47}}\end{array}$ \\
\hline $\begin{array}{l}\text { Transverse } \\
\text { Young's } \\
\text { modulus }\left(E_{2}\right)\end{array}$ & 7.79 & 1.58 & 11.46 & 4 & 4 & $\begin{array}{l}([71] /[72]) \\
{[83][88]}\end{array}$ & {$[81]^{47}$} \\
\hline $\begin{array}{l}\text { Shear } \\
\text { modulus } \\
\left(G_{12}\right)\end{array}$ & 4.32 & 4.32 & 4.32 & 1 & 1 & [83] & {$[81]^{47}$} \\
\hline $\begin{array}{l}\text { Poisson's } \\
\text { ration }\left(v_{12}\right)\end{array}$ & 4.60 & 4.60 & 4.60 & 1 & 2 & $([71] /[72])$ & {$[81]^{47}$} \\
\hline $\begin{array}{l}\text { Longitudinal } \\
\text { tensile } \\
\text { strength }\left(X_{t}\right)\end{array}$ & 8.45 & 4.20 & 16.28 & 6 & 7 & $\begin{array}{l}{[20][38]} \\
{[3][45]} \\
([71] /[72]) \\
{[86]}\end{array}$ & {$[81]^{47}$} \\
\hline $\begin{array}{l}\text { Transverse } \\
\text { tensile } \\
\text { strength }\left(Y_{t}\right)\end{array}$ & 9.34 & 7.13 & 13.20 & 3 & 3 & $\begin{array}{l}([71] /[72]) \\
{[88]}\end{array}$ & {$[81]^{47}$} \\
\hline $\begin{array}{l}\text { Longitudinal } \\
\text { compressive } \\
\text { strength }\left(X_{c}\right)\end{array}$ & 10.00 & $4.20^{* * *}$ & $16.28^{+}$ & 1 & 1 & {$[81]^{48}$} & \\
\hline $\begin{array}{l}\text { Transverse } \\
\text { compressive } \\
\text { strength }\left(\mathrm{Y}_{\mathrm{c}}\right)\end{array}$ & 10.00 & $4.20^{* * *}$ & $16.28^{+}$ & 1 & 1 & {$[81]^{48}$} & \\
\hline
\end{tabular}

\footnotetext{
${ }^{46}$ The data for $E_{1}$ is discarded by the box plot as a maximum outlier and the associated CoV is discarded

${ }^{47}$ The values for the CoV are assumed and not determined

48 No value are found in the literature except an assumption in Sanchez-Heres et al. [12]
} 


\begin{tabular}{|l|l|l|l|l|l|l|l|}
\hline $\begin{array}{l}\text { Shear } \\
\text { strength } \\
\left(\mathbf{S}_{12}\right)\end{array}$ & 7.32 & $4.20^{* * *}$ & $16.28^{+}$ & 1 & 1 & {$[58]$} & \\
\hline
\end{tabular}

*** lowest variation from strength values

+ highest variation from strength values

The mean coefficients of variation for E-glass laminate mechanical properties are between $4.32 \%$ and $10 \%$. The minimum values are low, especially for the longitudinal and transverse Young's moduli at $2.92 \%$ and $1.58 \%$ respectively, which seems unrealistically low. The maximum variation is for the longitudinal tensile strength, with a coefficient of variation of $16.28 \%$. These values are in accordance with Lekou and Philippidis [4] who determine the coefficients of variation for the mechanical properties of UD E-glass polyester manufactured by hand lay-up and obtain values between $8.94 \%$ to $24.90 \%$ based on 26 specimens. The values for the shear modulus and Poisson's ratio are based on one study and therefore may not be representative.

Flax composites are often seen as highly variable, however the coefficients of variation are similar to E-glass with all the mean values below $8 \%$ for flax compared to $10 \%$ for E-glass. This comparable variability at the laminate scale between flax and E-glass confirms the results demonstrated by Blanchard et al. [7] who state that there is little difference in variability at this scale. The maximum variability is also in the same range with a maximum value of $16.37 \%$ for the flax coefficient of variation compared to $16.28 \%$ for E-glass.

\subsection{Manufacturing techniques}

Through the analysis of this data a wide range of values are shown for the different mechanical properties. To ensure that a reasonable spread of data is used the analysis combines values from number of different manufacturing techniques which influence the achievable fibre volume fraction and therefore the mechanical properties of the composites. A large range of manufacturing techniques from inexpensive hand lay-up to more expensive closed mould techniques are used to manufacture natural fibre reinforced composites and Figure 1 illustrates how much the fibre volume fractions are influenced by the manufacturing technique. 


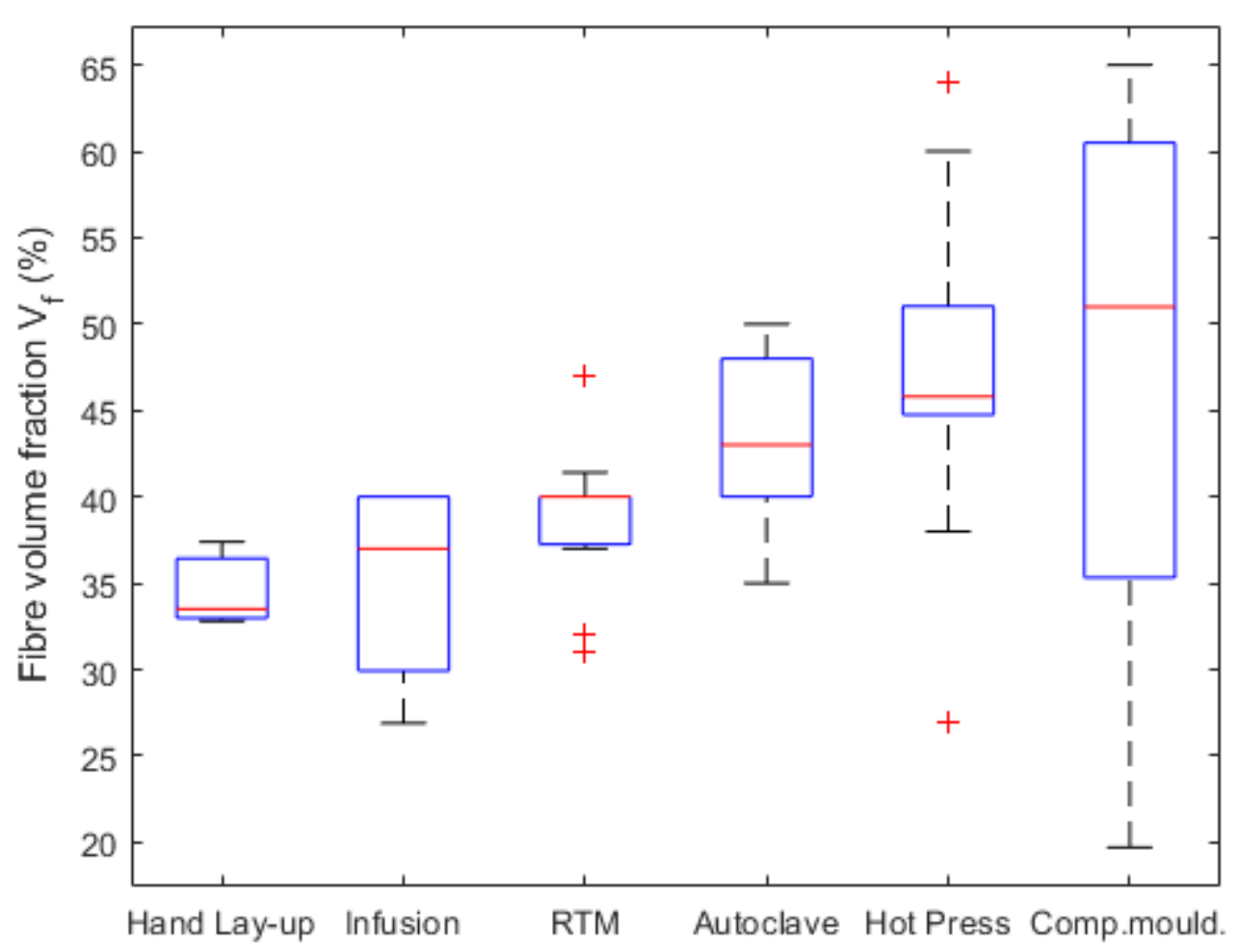

Figure 1: Fibre volume fraction $\left(V_{f}\right)$ obtained for flax/epoxy laminates with different manufacturing techniques

It is expected that for improved manufacturing techniques the variability decreases but due to the large number of studies using expensive manufacturing techniques such as compression moulding, 13 studies, and hot press, 25 studies, compared to hand lay-up with only 3 references, it is difficult to determine the influence of the manufacturing techniques on the range of properties. Despite the difference in the mean value of the volume fraction between the specimens manufactured by hand lay-up and those manufactured by compression moulding, the lowest value, $19.70 \%$, and highest value, $65 \%$, are both for specimens manufactured with compression moulding. The large range of data for compression moulding can be explained by the difference in applied pressure between the different studies, which also substantially affects the cost of manufacture. A common issue in the literature is the low fibre volume fractions exhibited by natural fibre reinforced composites, Shah et al. [38]. This is supported by the analysis of the data with a mean volume fraction of $34.57 \%$ for flax epoxy composites manufactured with hand lay-up compared to $62.5 \%$ for E-glass. Higher fibre volume fractions, $47.46 \%$ and $47.65 \%$, can be obtained with expensive manufacturing techniques such as compression moulding and hot press but these techniques are unlikely to be selected if the current structure is made of E-glass and replaced by flax as they will make the components too expensive. It is likely that large structural components will be manufactured using hand layup or resin infusion, with some more expensive applications autoclaving prepreg laminates. As the fibre volume fraction influences the mechanical properties, the longitudinal Young's modulus obtained for different manufacturing techniques are presented in Figure 2. 


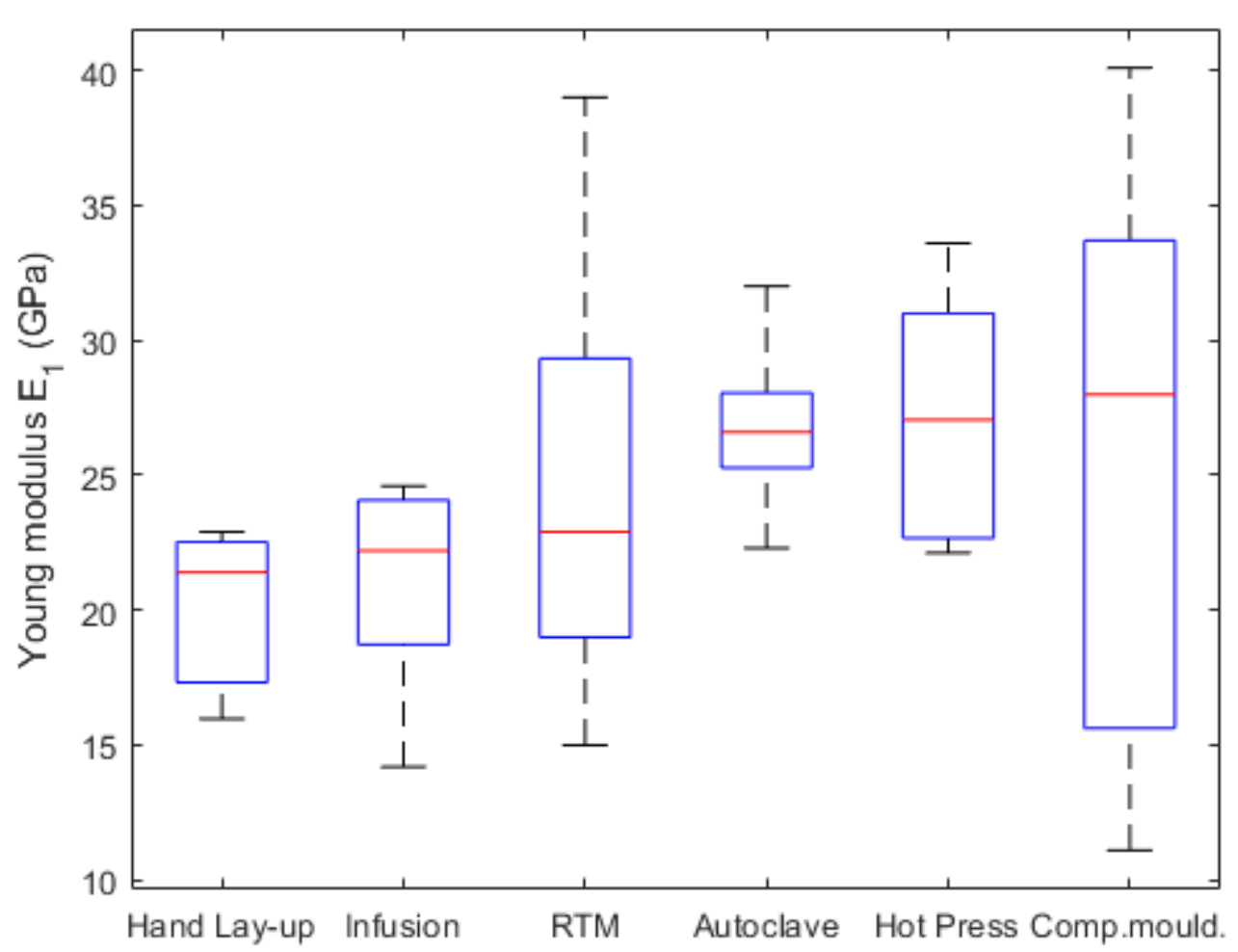

Figure 2: Flax /epoxy laminates longitudinal Young modulus $E_{1}(\mathrm{GPa})$ obtained with different manufacturing techniques from the literature

As expected the manufacturing technique has a large influence on the longitudinal Young's modulus with a mean stiffness of 20.1 GPa for hand lay-up and 27.1 GPa for specimens manufactured by hot plate. This difference can be explained by the higher fibre volume fractions and lower void contents obtained with more expensive manufacturing techniques as an increase in pressure produces plates with lower porosities and higher mechanical properties as shown by Phillips et al. [98] and Li et al. [32]. The minimum, $11.1 \mathrm{GPa}$, and maximum value, $40.10 \mathrm{GPa}$, are both obtained by compression moulding, again showing a larger range than other techniques due to the number of pressures tested at and the large number of references using compression moulding. The range of coefficients of variation reported in the literature is similar for all manufacturing techniques with mean values around $5 \%$ except for compression moulding with a mean variation of $11 \%$. The influence of the manufacturing techniques on the longitudinal breaking strength are presented in Figure 3. 


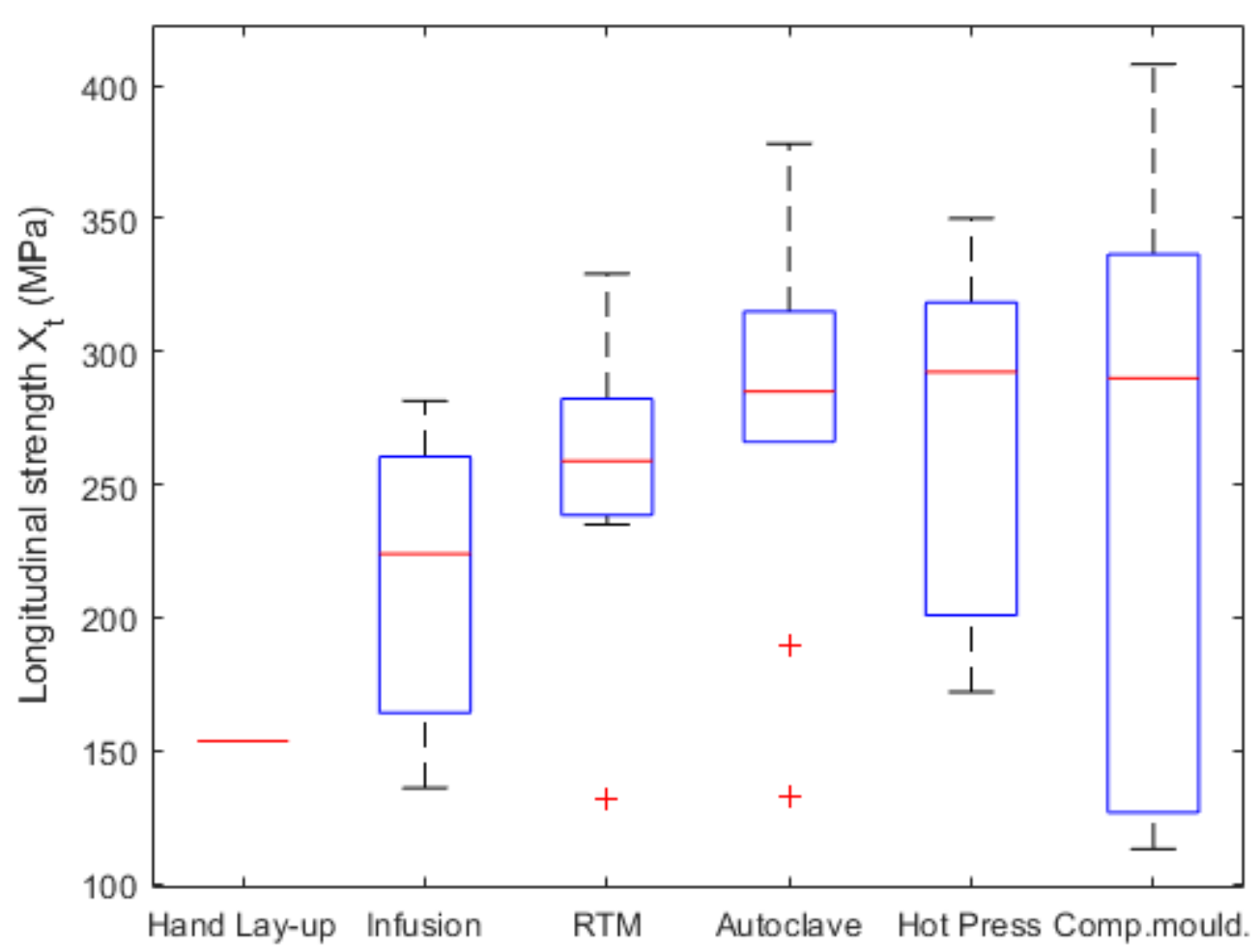

Figure 3: Longitudinal tensile breaking strength $\mathrm{X}_{t}(\mathrm{MPa})$ obtained with different manufacturing techniques for flax fibre reinforced epoxy laminates from the literature.

The relationship between manufacturing techniques and the fibre volume fraction in Figure 1 and the longitudinal Young's modulus in Figure 2 is less clear for the longitudinal strength. The mean values for the longitudinal tensile strength ranges from 153.6 MPa for hand Lay-up to 296.44 MPa for laminates manufactured with autoclave. The maximum value of $408 \mathrm{MPa}$ is obtained with compression moulding which shows the largest spread of strength values. The spread of data can also be caused by the larger number of studies, 13, using compression moulding as a manufacturing technique. Only one study uses hand lay-up as a manufacturing technique, meaning that the value may not be representative of values probable in industry. The mean values for the coefficients of variation reported in the literature are more spread than for the Young's modulus with a mean value of $2.7 \%$ for resin infusion compared to $8.6 \%$ for autoclave.

\subsection{Summary}

The mean flax laminate Young's modulus is $38 \%$ lower than the E-glass and the mean longitudinal tensile strength for flax laminates is $75 \%$ lower, a large drop in mechanical properties. These values show a much larger difference than when comparisons are performed at the fibre scale, where the majority of testing is currently performed in the literature. However, the variability of natural composites, which is often documented as being problematic, is similar to E-glass at the laminate scale. Most studies focus on the tensile Young's modulus but the longitudinal tensile strength has a higher impact on the probability of failure than the Young's modulus for a strength limit state as shown by Yang et al. [99] who find that the strength is the most influential parameter with a sensitivity factor of 0.72 compared to 0.14 for the fibre's modulus. Flax epoxy mechanical properties 
are well characterised in longitudinal tension but less characterised in the transverse direction, especially compression and shear; though these properties are less important for many structural applications. A large proportion of the data is for properties generated using more expensive manufacturing techniques, more commonly used to manufacture carbon structures which are unlikely to be replaced by flax but more realistic manufacturing options, like resin infusion, are poorly documented. A combination of these factors inflates the mechanical properties to values that are unlikely to be seen in industrial applications and provides an unfair analysis in comparison to flax at the material scale, though limited studies are performed to see how these differences affect the structural behaviour. Fibre scale properties are often used in the rule of mixtures to obtain laminate properties in initial calculations for standard composites [100]. However, for flax fibre laminates a number of authors, Charlet et al. [101], Shah et al. [102], Charlet et al. [24], Shah [19] and Moothoo et al. [103], investigate the accuracy of the rule of mixtures and it can be concluded that the obtained results are inconsistent. Despite this a large proportion of the literature focusses on fibre properties with 6169 data points for the Young's modulus at the elemental fibre scale. For structural applications, engineers and designers need reliable mechanical properties to implement in structural analysis and therefore laminate scale data are required.

\section{Reliability analysis of natural composites for structural applications}

\subsection{Monte Carlo Simulation}

The reliability analysis of a grillage structure is conducted to compare flax and E-glass fibre reinforced composites. Different techniques can be used for reliability studies such as Monte-Carlo simulations, First Order and Second Order Reliability methods. For this study, a Monte-Carlo simulation is selected based on the same method proposed by Sobey et al. [104]. It is an accurate technique which can solve complex problems and predict the future behaviour of structures for which the probability distributions of the basic variables are known [105]. The methodology is presented in Figure 4. 


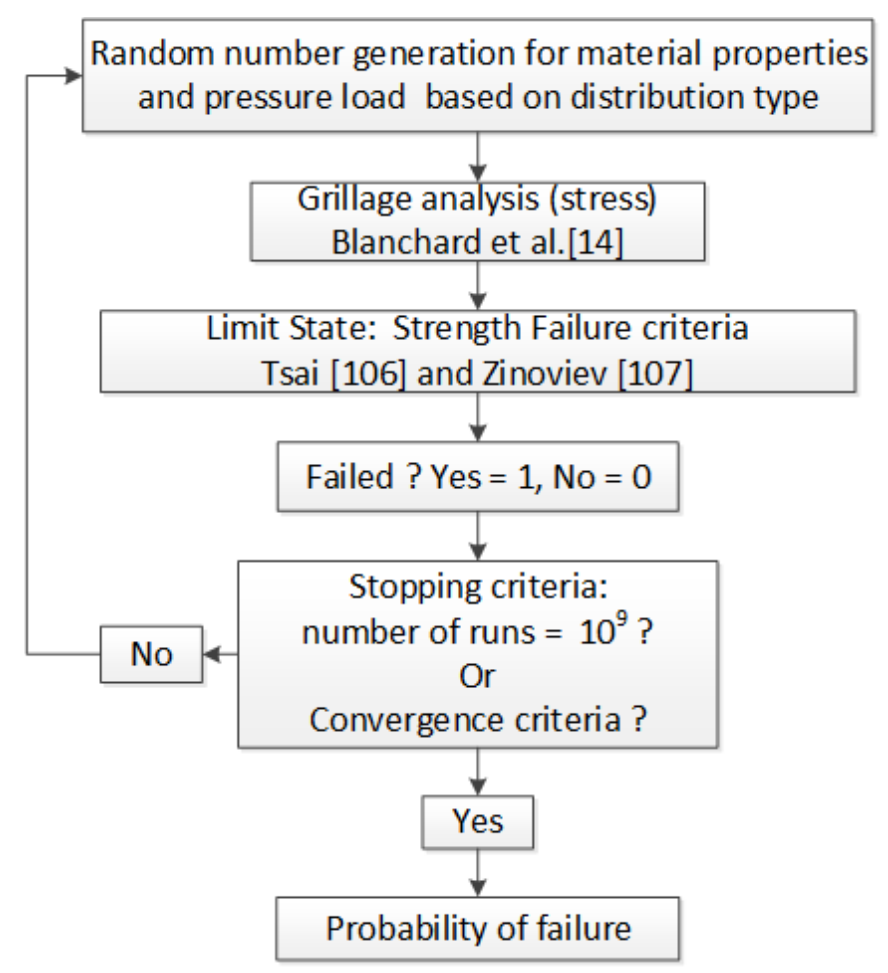

Figure 4: Reliability assessment method for composite grillages

The first step of the Monte-Carlo simulation is to populate the inputs for the first structural assessment. The material properties are generated using a normally distributed random seeding with mean values and coefficients of variation generated from the review of the literature. The tails are discarded, as shown in Palmer [108], to remove unrealistically high or low values. The pressure is also randomly generated with a mean value of $110 \mathrm{kPa}$, the design load for the application. It follows a Weibull distribution with a variation of $15 \%$ [104]. The structural response of the grillage structure, including the stresses, can then be calculated. This is performed according to a rapid analytical calculation used in Sobey et al. [104] with an updated formula developed by Blanchard et al. [14] which can account for the change in structural response exhibited by low stiffness materials such as flax; this approach has been shown to be within 5\% accuracy of FEA based on the variable range used in the simulations. The third step it to compare the stresses to the failure criteria to determine if the grillage is failing based on first ply failure. The probability of failure is calculated from the total number of failed structures divided by the number of grillages assessed at that point. The simulations are stopped at $10^{9}$ or when the probability of failure has converged, which is judged to be when the difference between the probabilities of failure at the last three orders of magnitude $\left(10^{n}, 10^{n+1}\right.$ and $\left.10^{n+2}\right)$ and the average probability of failure for those three steps, are all smaller than $5 \%$.

The failure of the panel is determined using strength failure criteria recommended by the World Wide Failure Exercise: Liu and Tsai [106] and Zinoviev et al. [107], on a first ply failure approach. Whilst it is also recommended to utilise the Puck or Cuntze failure criteria in addition to these criteria neither is selected due to the large number of data required to accurately assess these criteria which is missing for natural fibres.

When considering the Tsai-Wu criterion, previous results show that the nominal value of $\mathrm{F}_{\mathrm{xy}}{ }^{*}=-0.5$ leads to good agreement for E-glass [106]. However for flax fibre reinforced epoxy laminates the 
failure envelope needs to be adjusted and the value of $\mathrm{F}_{\mathrm{xy}}{ }^{*}$ is set to 0 as optimised by Koh and Madsen [21]. The optimisation is based on limited experimental data with only 3 specimens for $Y_{t}$ and $X_{c}$ and 2 specimens for $Y_{c}$. To demonstrate the difference in behaviour with the change in $F_{x y}{ }^{*}$ the Zinoviev failure envelope is plotted in black and the Tsai failure envelope is plotted in grey for $\mathrm{E}-$ glass in Figure 5 a) and flax in Figure $5 \mathrm{~b}$ ) using the mean strength properties. The failure occurs when the response is outside one or both coloured regions.

a)

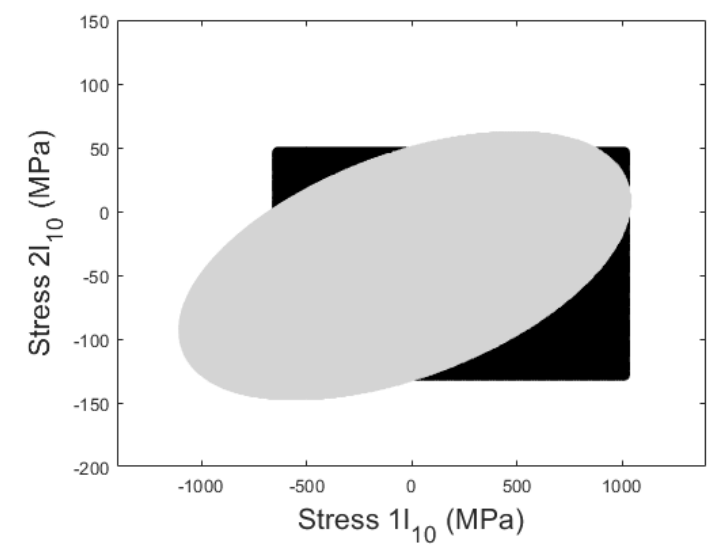

b)

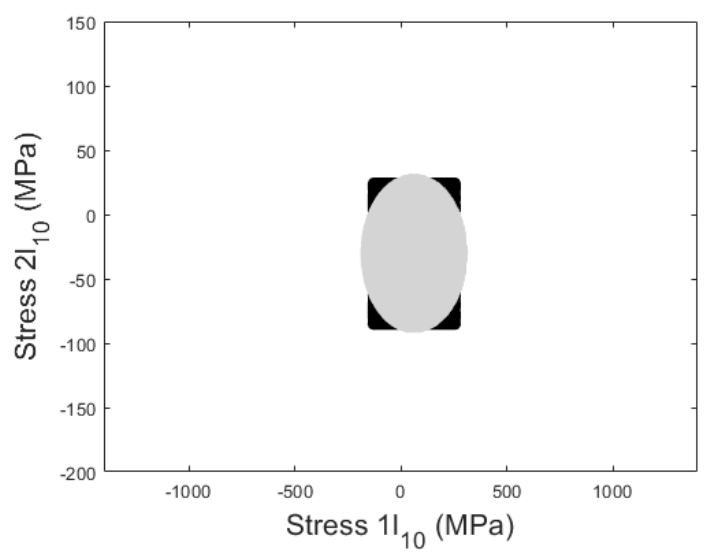

Figure 5: a) failure envelope for E-glass mean values b) failure envelope for flax mean values

The change in $\mathrm{F}_{\mathrm{xy}}{ }^{*}$ creates differences in the shape of the failure envelopes between the E-glass and flax laminates, with flax more likely to fail in tension/tension and compression/compression but less likely to fail in tension/compression than E-glass. In this study, no failures are recorded in pure compression and most failures are recorded in pure tension with low transverse stresses. This means that for this application the difference in shape has a limited impact on the probability of failure of the structure. However, the Tsai failure criterion needs more refinement to ensure safe application of natural composites especially if complex loadings or lay-ups are utilised.

\subsection{Grillage topology}

A grillage structure, presented in Figure 6, is selected as a typical component in many structural applications. The stiffened plate is modelled using the Navier method grillage analysis taken from Vedeler [109] and empirically adapted for grillage structures made of composite materials by Blanchard et al. [14]. The adapted Navier grillage analysis calculates the deflection at intersecting points between longitudinal beams and transverse girders. The selected grillage topology is based on secondary stiffeners taken from a marine application and is composed of 2 identical longitudinal and transverse stiffeners, designed with a [0/90] symmetric lay-up. The material properties vary between the longitudinal and transverse stiffeners, to reflect the construction typical for the structures where stiffeners are constructed separately and post-cured to the plate. The geometry of the panel is fixed to identify the impact of the material properties rather than the geometric imperfections. 


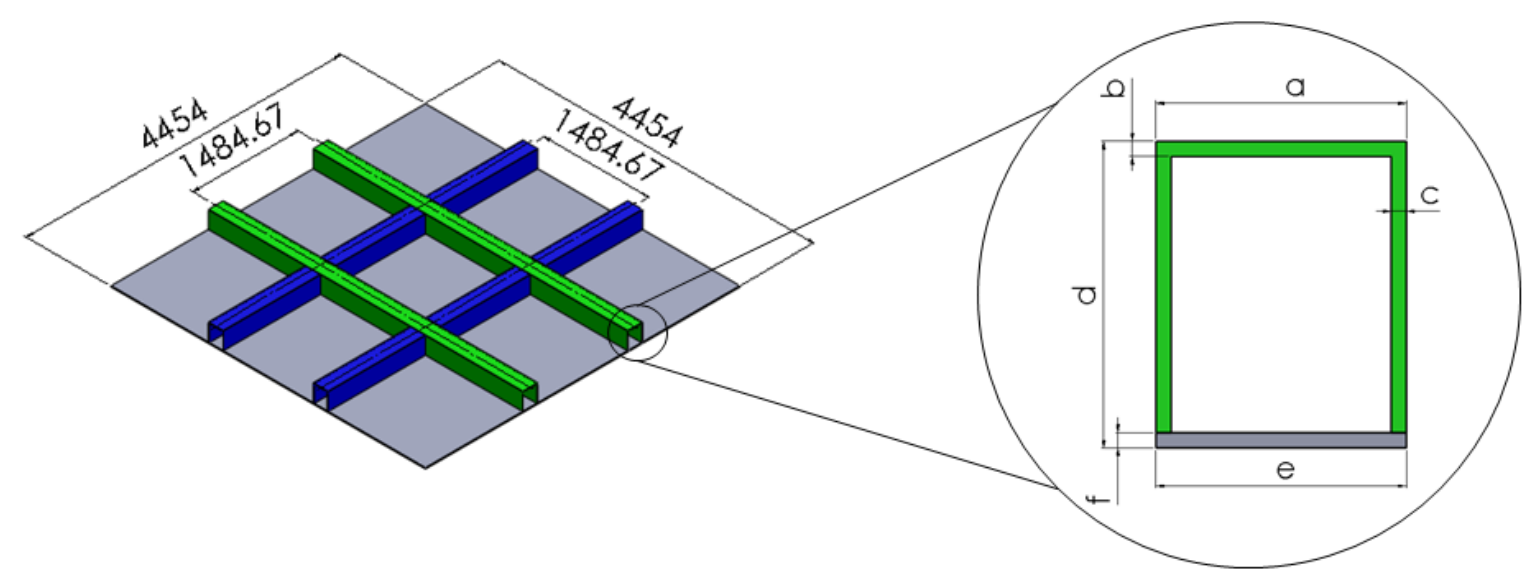

Figure 6: Grillage structure and stiffener dimensions

One of the main advantages of flax fibre reinforced composites is their low density compared to conventional composites, even if the lower fibre volume fraction reduces this benefit. To consider the difference in density between E-glass and flax fibre reinforced composites two design constraints are used: one where the volume of the two grillages is the same and one where the mass is equivalent, to show how to take advantage of the low flax density. For the volume constrained approach, the dimensions of both structures are identical and the flax/epoxy grillage is lighter because of the lower density of flax laminates. For the mass constrained approach, the thickness of the flax/epoxy laminate is increased equally on the plate and the stiffener's webs and crown to reach a mass comparable to the E-glass/epoxy grillage; the volume of the flax fibre reinforced epoxy composite structure is then larger than the E-glass/epoxy structure for the same mass. The dimensions, masses and volumes of the resulting grillages are presented in Table 5.

Table 5: Dimensions of the grillage structure

\begin{tabular}{lcccc} 
& & E-glass / Epoxy & $\begin{array}{c}\text { Flax / Epoxy } \\
\text { (same volume) }\end{array}$ & $\begin{array}{c}\text { Flax / Epoxy } \\
\text { (same mass) }\end{array}$ \\
\hline Crown width $(\mathrm{mm})$ & a & 211 & 211 & 223.2 \\
\hline Crown thickness $(\mathrm{mm})$ & b & 12.84 & 12.84 & 18.94 \\
\hline Web thickness $(\mathrm{mm})$ & $\mathrm{c}$ & 12.84 & 12.84 & 18.94 \\
\hline Web height $(\mathrm{mm})$ & $\mathrm{d}$ & 258 & 258 & 270.2 \\
\hline Flange width $(\mathrm{mm})$ & $\mathrm{e}$ & 211 & 211 & 223.2 \\
\hline Plate thickness $(\mathrm{mm})$ & $\mathrm{f}$ & 12.84 & 12.84 & 18.94 \\
\hline Length $(\mathrm{mm})$ & & 4454 & 4454 & 4454 \\
\hline Volume $\left(\mathrm{m}^{3}\right)$ & & 0.40 & 0.40 & 0.60 \\
\hline Mass $(\mathrm{kg})$ & & 755 & 508 & 754 \\
\hline
\end{tabular}


The dimensions of the mass constrained flax/epoxy grillage structure is calculated with the average density of the composites for both materials, assuming no void content. $V_{f}$ is the average fibre volume fraction selected as $54.42 \%$ for E-glass and $43.64 \%$ for flax reinforced epoxy from Table 1 and Table 3. A value of $1.089 \mathrm{~g} / \mathrm{cm}^{3}$ is used for the epoxy density based on the properties of the PRIME $^{\mathrm{TM}} 20$ LV with fast hardener from Gurit. A representative value from the literature of 2.54 $\mathrm{g} / \mathrm{cm}^{3}$ is selected for the density of E-glass fibres [1] [33] [96] [110]. The variability in flax fibre densities available in the literature is large with values ranging from $1.287 \mathrm{~g} / \mathrm{cm}^{3}[111]$ to $1.59 \mathrm{~g} / \mathrm{cm}^{3}$ [10] measured with different methods. An average value for flax fibre density of $1.49 \mathrm{~g} / \mathrm{cm}^{3}$ is used based on experiments performed with 10 measurements by gas pycnometer by Amiri et al. [112] as this method is judged to be more accurate and less variable than others. From these values a density of E-glass fibre reinforced epoxy laminate is calculated equal to $1879 \mathrm{~kg} / \mathrm{m}^{3}$ and the density of flax fibre reinforced epoxy laminate is equal to $1264 \mathrm{~kg} / \mathrm{m}^{3}$.

\section{Comparison of E-glass and flax composites structural properties}

The reliability analysis of a flax structure is compared to a conventional composite to investigate the potential to replace E-glass with more sustainable materials in structural applications. Since the structure is originally taken from a marine application an acceptable range of probabilities of failure is defined based on those commonly seen in the marine industry where the target is between $10^{-4}$ and $10^{-6}[113]$. These values are set based on consideration of all failure modes, final failure including fatigue, and it is anticipated that the values in this analysis should therefore be considerably safer than these values, as only first ply failure is considered.

\subsection{Equal volume}

The probability of failures and deflections for grillage structures made of flax composites with the same volume as the E-glass grillage are presented in Table 6 and compared to the values for E-glass.

Table 6: Probability of failure for flax grillage with the same volume as E-glass

\begin{tabular}{|c|c|c|c|c|c|}
\hline Variables & CoV & Flax $P_{f}$ & $\begin{array}{c}\text { Flax mean } \\
\text { deflection } \\
(\mathrm{mm})\end{array}$ & E-glass $P_{f}$ & $\begin{array}{c}\text { E-glass mean } \\
\text { deflection } \\
(\mathrm{mm})\end{array}$ \\
\hline \multirow{3}{*}{ Min } & Min & $1.00 \mathrm{E}+00$ & \multirow{3}{*}{466} & $0.00 \mathrm{E}+00$ & \multirow{3}{*}{171} \\
\hline & Mean & $1.00 \mathrm{E}+00$ & & $6.29 \mathrm{E}-06$ & \\
\hline & Max & $1.00 \mathrm{E}+00$ & & $7.46 \mathrm{E}-03$ & \\
\hline \multirow{3}{*}{ Mean } & Min & $8.59 \mathrm{E}-01$ & \multirow{3}{*}{227} & $0.00 \mathrm{E}+00$ & \multirow{3}{*}{128} \\
\hline & Mean & 9.07E-01 & & $0.00 \mathrm{E}+00$ & \\
\hline & Max & 9.49E-01 & & $9.51 \mathrm{E}-06$ & \\
\hline \multirow{3}{*}{ Max } & Min & $6.90 \mathrm{E}-03$ & \multirow{3}{*}{147} & $0.00 \mathrm{E}+00$ & \multirow{3}{*}{96} \\
\hline & Mean & $9.23 \mathrm{E}-02$ & & $0.00 \mathrm{E}+00$ & \\
\hline & Max & $3.83 \mathrm{E}-01$ & & $1.54 \mathrm{E}-06$ & \\
\hline
\end{tabular}


The probability of failure of the E-glass panel is low with almost all the configurations failing at $10^{-6}$ to less than $10^{-9}$ except for one case where the variables are set to their minimum and have the maximum coefficient of variation. This is below the probability of failure common in the marine industry, but this analysis only considers intact properties with no fatigue indicating that the minimum properties for the E-glass and the higher coefficients of variation might be unrealistic. The coefficients of variation have a large influence on the reliability of the structure especially when the mechanical properties are low as it can be seen in Figure 7. For high mechanical properties, the variation has no influence as even with the maximum coefficients of variation the mechanical properties are in the safe zone. However for lower mechanical properties closer to the failure limit, an increase in variability has a large impact.

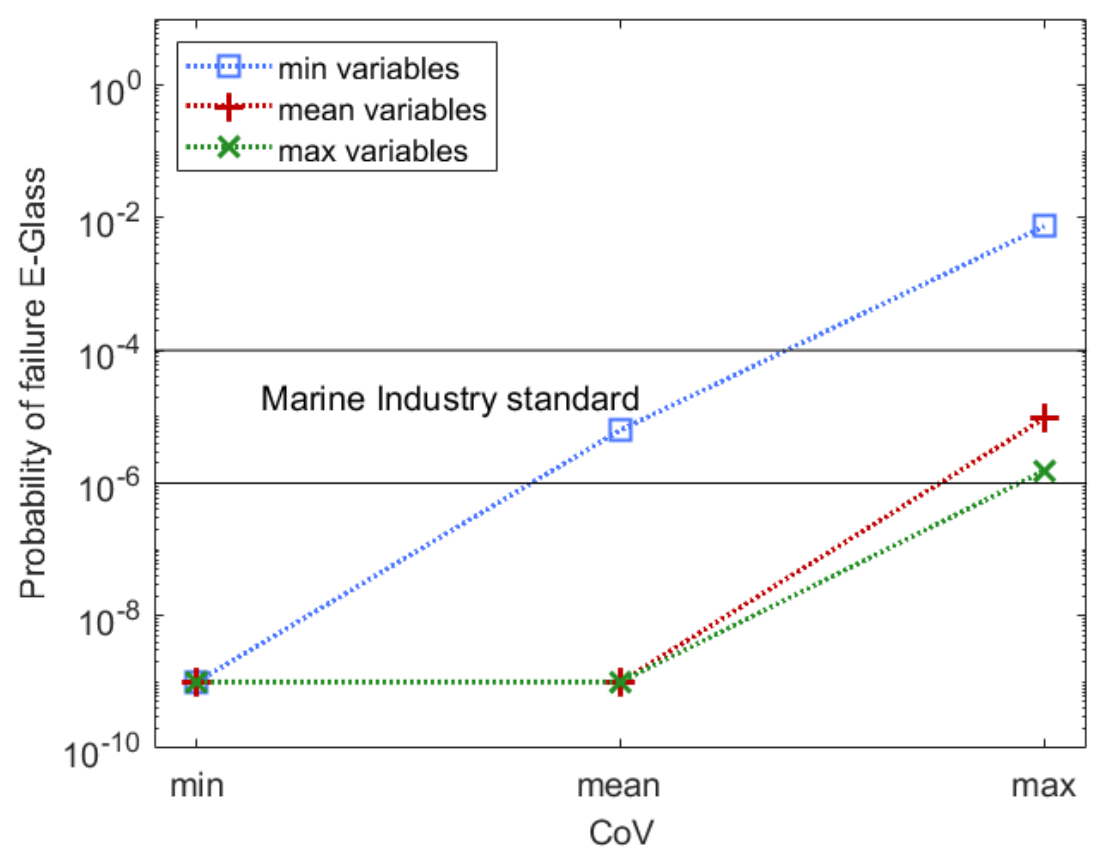

Figure 7: Probabilities of failure of E-glass structures for different mechanical properties and CoV

For a flax fibre reinforced epoxy structure with an equivalent volume to the E-glass structure, the probability of failure of the flax laminates are unacceptably high for all the cases and cannot provide a safe panel. The probability of failure is above 0.9 for the cases with minimum or average mechanical properties and $6.9 \times 10^{-3}$ for the "safest" configuration, maximum properties and minimum coefficients of variation, despite this only being a first ply failure estimate. However, the panel made of flax is lighter than the E-glass equivalent and there are less volume constrained applications than mass constrained ones; therefore a mass constrained approach is investigated.

\subsection{Equal mass}

A grillage structure with the same mass as the E-glass structure, but a larger volume, is investigated to determine the feasibility of flax fibre reinforced laminates for structures constrained by mass. This is to take advantage of the low densities exhibited by flax fibres, giving them the greatest opportunity to be used in applications; the probabilities of failure and mean deflections are presented in Table 7 where the E-glass values remain the same as no changes are made to this structure. 
Table 7: Probability of failure for flax grillage with the same mass as E-glass

\begin{tabular}{|c|c|c|c|c|c|}
\hline Variables & $\mathrm{CoV}$ & Flax $P_{f}$ & $\begin{array}{c}\text { Flax mean } \\
\text { deflection } \\
(\mathrm{mm})\end{array}$ & E-glass $P_{f}$ & $\begin{array}{l}\text { E-glass mean } \\
\text { deflection } \\
(\mathrm{mm})\end{array}$ \\
\hline \multirow{3}{*}{ Min } & Min & 9.99E-01 & \multirow{3}{*}{291} & $0.00 E+00$ & \multirow{3}{*}{171} \\
\hline & Mean & $1.00 \mathrm{E}+00$ & & $6.29 \mathrm{E}-06$ & \\
\hline & Max & $1.00 \mathrm{E}+00$ & & 7.46E-03 & \\
\hline \multirow{3}{*}{ Mean } & Min & $9.40 \mathrm{E}-03$ & \multirow{3}{*}{142} & $0.00 \mathrm{E}+00$ & \multirow{3}{*}{128} \\
\hline & Mean & $9.01 \mathrm{E}-02$ & & $0.00 E+00$ & \\
\hline & Max & $3.71 \mathrm{E}-01$ & & $9.51 \mathrm{E}-06$ & \\
\hline \multirow{3}{*}{ Max } & Min & $0.00 \mathrm{E}+00$ & \multirow{3}{*}{92} & $0.00 E+00$ & \multirow{3}{*}{96} \\
\hline & Mean & $1.15 \mathrm{E}-07$ & & $0.00 E+00$ & \\
\hline & Max & $8.30 \mathrm{E}-03$ & & $1.54 \mathrm{E}-06$ & \\
\hline
\end{tabular}

The increase in thickness of the flax laminates, to match the mass of the E-glass structure, has a large impact on the probabilities of failure. The flax structure with the mean variables and mean coefficients of variation exhibit a decrease in probability of failure by a factor of 10 . The large range of mechanical properties for flax translates to a large range of probabilities of failure, from unacceptable for the minimum variables cases to very safe for the maximum variables; a larger range than for the E-glass cases. Even if the probabilities of failure are higher than the E-glass mass equivalents the flax structures show some probability of failures below the $10^{-6}$ safety recommendation, though only for the cases with maximum mechanical properties. The influence of the variables and the coefficients of variation on the probabilities of failure are presented in Figure 8.

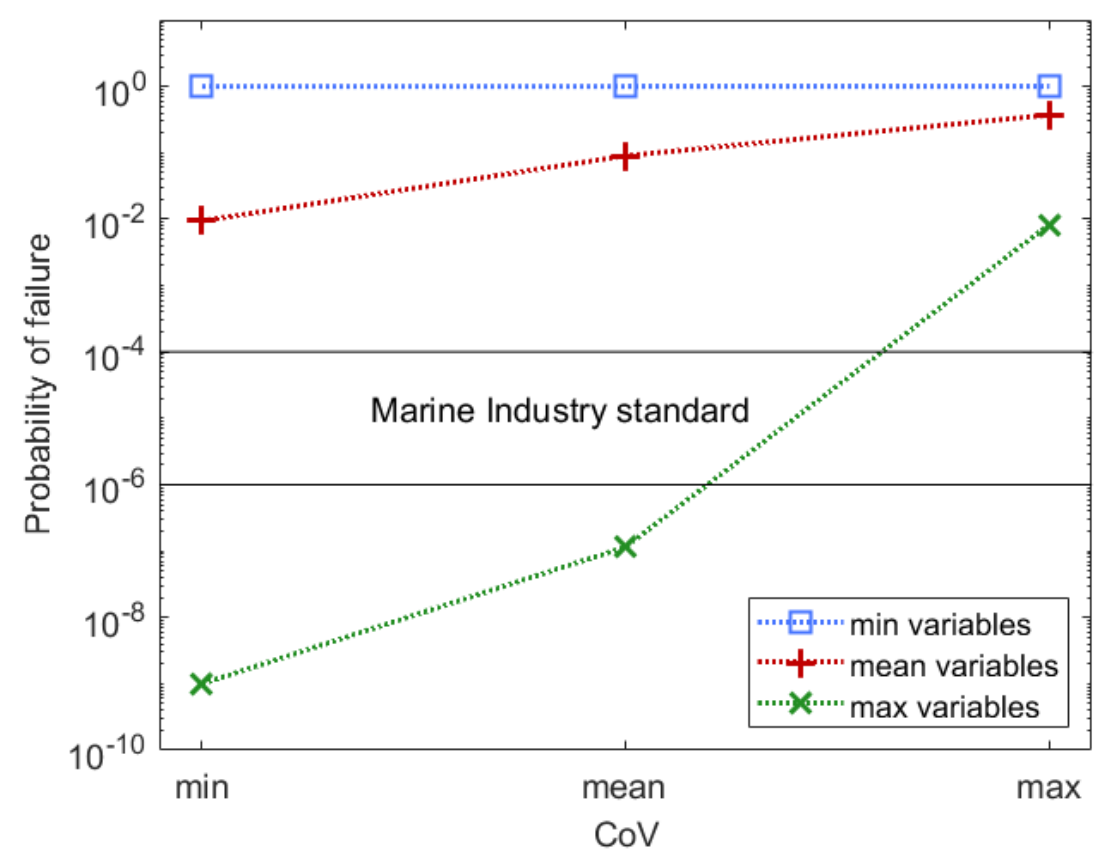

Figure 8: Probabilities of failure of flax structures for an equivalent mass to E-glass 
In most cases the variability of the mechanical properties has a limited influence as the panels will fail due to the poor mechanical properties of the flax. However, in the case of the maximum mechanical properties the variability has a larger influence. It indicates that if the maximum properties with minimum coefficients of variation from the literature are reproducible, flax structures might be feasible for some applications as no failures occurred. However, these values are deemed to be quite unlikely, as they are generated in laboratory conditions. Whilst these values indicate some potential they do not exhibit an equivalent factor of safety as for the E-glass and therefore a flax structure is derived that is as safe as E-glass using the mean properties.

\subsection{Feasibility study}

The mass of the flax structure is increased to find a geometry with an equivalent reliability, using the mean properties and coefficients of variation. Figure 9 demonstrates how the additional mass affects the probability of failure.

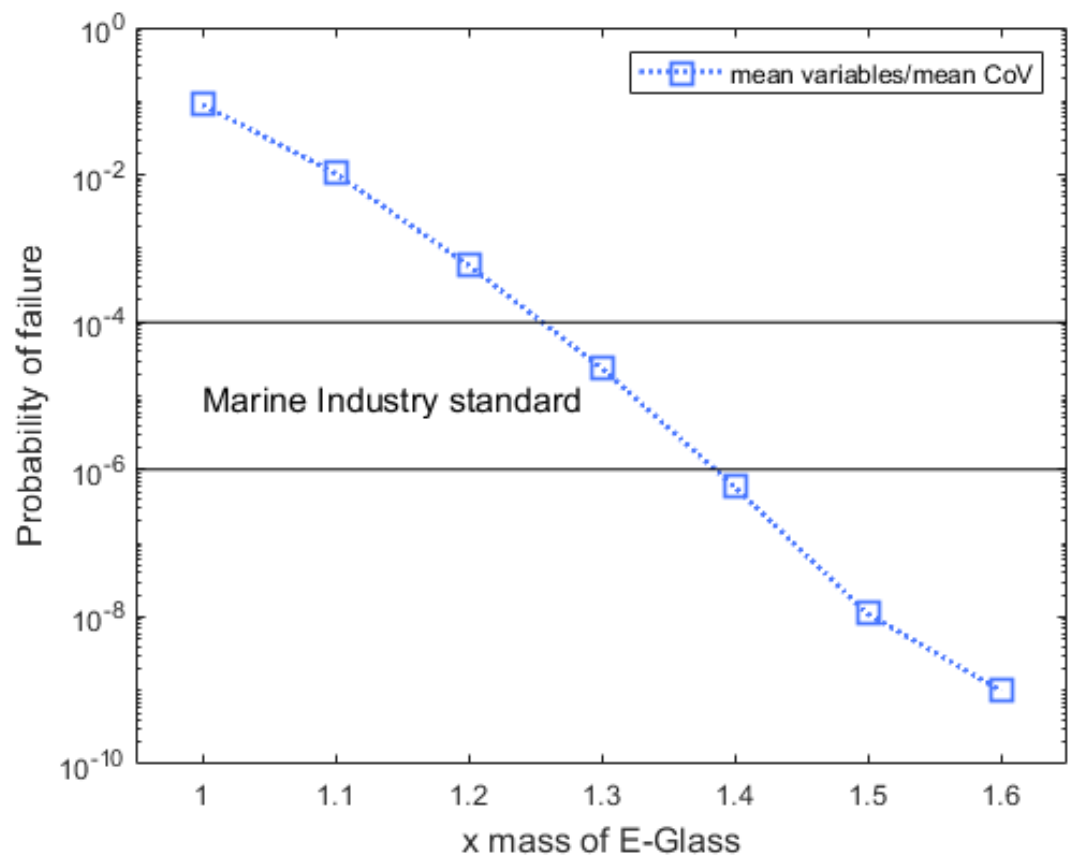

Figure 9: Probability of failure for flax structures compared to the mass of the E-glass structure

For the mean flax mechanical properties and mean variability, the structure needs to be $30 \%$ heavier than the E-glass structure to meet the marine industry standard. However, at this mass the flax and E-glass structures are not equivalent with a probability of failure smaller than $10^{-9}$ for the E-glass panel compared to $2.52 \times 10^{-5}$ for the flax panel.

As the probability of failure for the E-glass panel is smaller than $10^{-9}$, it is difficult to determine how safe the E-glass structure is compared to flax. For this purpose, the mean stress to mean strength ratio after convergence is calculated for both structures. To obtain the same ratio, the flax structure needs to be 2.4 times heavier and $257 \%$ larger, $0.4 \mathrm{~m}^{3}$ compared to $1.4 \mathrm{~m}^{3}$, than E-glass, a considerable weight and volume increase which can be seen in the different cross-sections presented in Figure 10. 


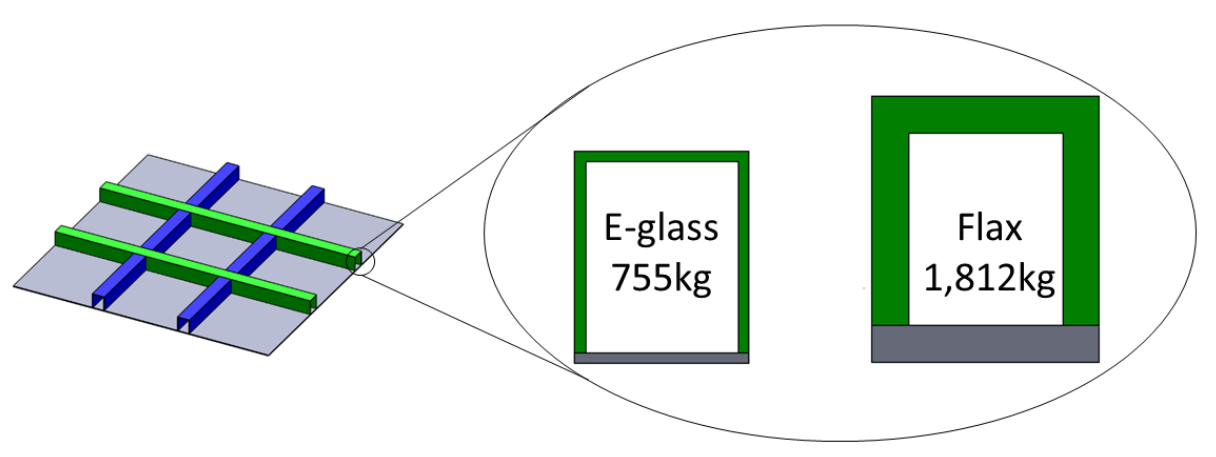

Figure 10: E-glass and flax stiffener cross-sections designed with equivalent reliability and total plate mass

\subsection{Impact of the manufacturing process on flax structural properties}

The manufacturing process has a large impact on the mechanical properties obtainable for a given material. The impact of the manufacturing techniques and therefore the reliability of the structure for three commonly used manufacturing techniques for E-glass structures: hand lay-up, resin infusion and autoclave is investigated on the grillage with the same mass as E-glass. The tensile properties, $E_{1}$ and $X_{T}$ are specific for each manufacturing process but due to a lack of data, and the low influence of the transverse and compressive properties on the reliability, the mean data from Table 1 are used for $E_{2}, Y_{T}, X_{C}, Y_{C}, S_{12}$ for all three cases. The average coefficients of variation from Table 2 are used for all the mechanical properties as the quantity of data available specifically for these three manufacturing techniques is insufficient to obtain representative values. The probabilities of failure for the three different manufacturing techniques with mean variables and mean coefficients of variation are presented in Figure 11 together with the probability of failure obtained with the combined manufacturing techniques.

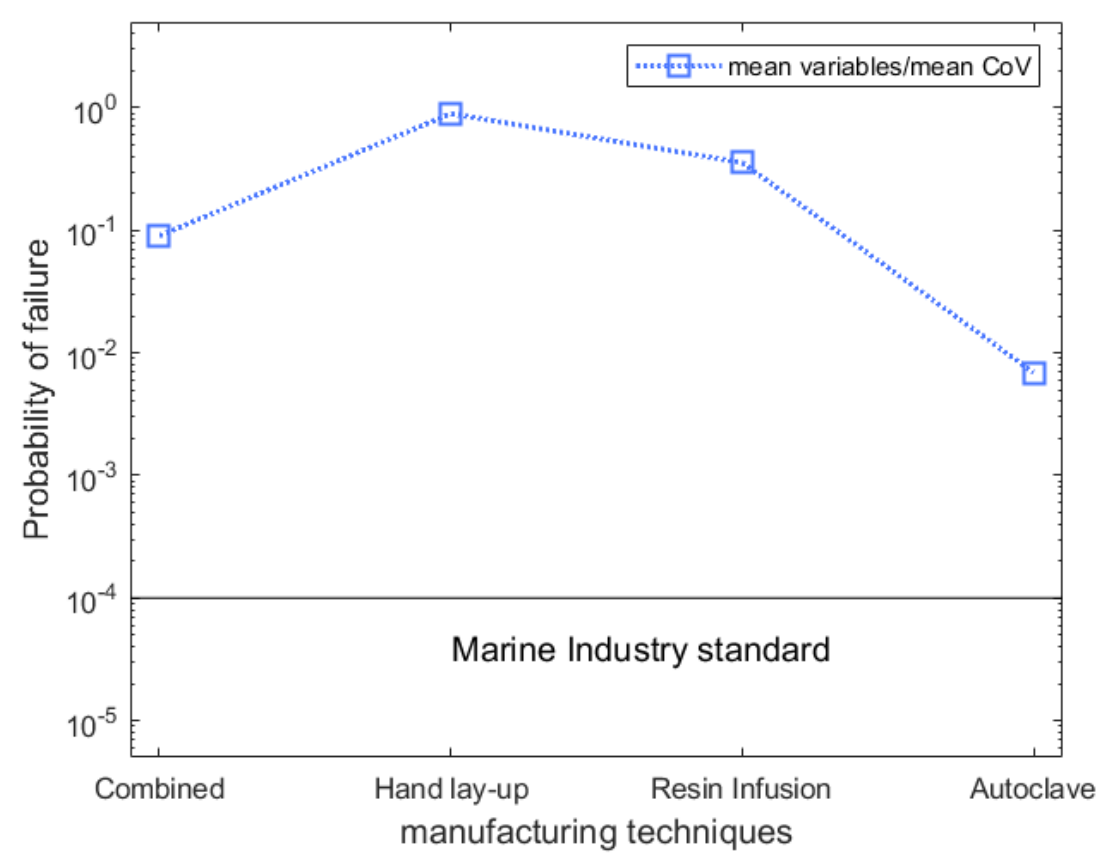

Figure 11: Probability of failure for a flax epoxy structure manufactured with hand lay-up, resin infusion and autoclave 
Figure 11 shows that the number of studies using expensive manufacturing techniques for flax fibre reinforced laminates reduces the probability of failure from that derived from the combined manufacturing techniques. This results in a probability of failure which is lower than would be expected when considering hand lay-up and resin infusion. The panel manufactured with prepreg and autoclave curing has the lowest probability of failure equal to $6.9 \times 10^{-3}$ which is still too high to be adequate for marine structures. Hand lay-up and resin infusion techniques which are widely used in the industry for E-glass structures are inadequate, therefore the estimates for the equivalent mass of 2.4 should be increased or the cost of these new sustainable structures will be substantially increased due to the utilisation of more expensive manufacturing techniques. It demonstrates the influence of the manufacturing techniques on the reliability of the structures and the importance to consider mechanical properties obtained with manufacturing techniques reproducible on an industrial scale for structures.

\section{Discussion and limitations}

There are a huge number of data points in the literature for flax fibre properties, $6000+$. However, the specific structure of flax fibres means that the data cannot be used for predictions of the properties at larger scales as the rule of mixtures is too inaccurate. At the laminate scale the number of data points is reduced but the range of these values for each property remains large; this is especially the case for the Young's modulus and the strength in the longitudinal direction with 58 points and a minimum of $11.86 \mathrm{MPa}$ and a maximum value of $40.10 \mathrm{MPa}$ for Young's Modulus and with 55 points and a minimum value of $113 \mathrm{MPa}$ and a maximum value of $408 \mathrm{MPa}$ for the strength in the longitudinal direction. Whilst some properties are relatively well understood there is a lack of data for the transverse and compressive properties, with only 4 points. The literature shows that the mechanical properties of flax laminates are lower than E-glass, 38\% for the average longitudinal Young's modulus and $75 \%$ for the average longitudinal tensile strength, but that the variability of both materials is similar. Some of the values near the maximum and minimum still seem to be unrealistic, where the minimum tensile transverse strength of the flax, $4.5 \mathrm{MPa}$, is so small that some plies are failing transversely for the configuration with the minimum mechanical properties. In addition data is missing for the Poisson's ratio, the shear modulus and shear strength but the influence of these properties on the final failure of this application is small. Much of the data gives optimistic values compared to that likely to be seen in industry as it is obtained from expensive manufacturing techniques, with less data for hand lay-up and resin infusion manufacturing which are more realistic for structural applications. More studies on transverse and compressive properties are required for structural analysis and a better understanding of the properties likely to be seen in industry is also required.

The reliability analysis is based on strength only but many applications have a serviceability limit state based on deflection, which is typically harder to meet for composite materials. Under this limit state flax laminates cannot compete against E-glass for volume constrained applications where the mean deflection for the E-glass grillage is $128 \mathrm{~mm}$ compared to $227 \mathrm{~mm}$ for the flax grillage. Based on an equivalent mass, the deflection of the flax structure is only $11 \%$ higher than E-glass with a mean deflection of $142 \mathrm{~mm}$ because of the bulkier laminate; the flax structure needs to be $10 \%$ heavier than E-glass to have an equivalent mean deflection. Furthermore, as demonstrated by Shah [114], the Young's modulus has a bi-linear shape and the initial stiffness of flax laminates decreases by up to $50 \%$ above $0.4 \%$ strain. The Young's modulus data available in the literature is likely to be 
taken at lower strains and therefore the stiffness is higher than would be seen in structural applications, making this comparison difficult at this stage.

Studies at the fibre scale advertise flax fibre Young's modulus as equivalent to E-glass and therefore that both materials have equivalent mechanical properties at the laminate and structural scales. At the laminate scale, the focus is on the longitudinal Young's modulus properties for which the highest value for flax is almost equal to the average value for E-glass. However, the longitudinal tensile strength, which has a much bigger impact on the reliability, is low with a value of $255 \mathrm{MPa}$ for flax compared to $1014 \mathrm{MPa}$ for E-glass reinforced laminates and these reliability analyses demonstrate that the potential for flax fibres to be used for structural applications is lower than indicated by much of the literature. An increase in mass of a structure by 2.4 seems to be unrealistic for many industries, and there will be efficiency implications for structures that add this much weight with a possible gain in emissions larger than the gains in sustainability at manufacture. For non-structural applications, where the flax provides a lightweight option, then there are many benefits for these materials.

The critical limitation for the utilisation of flax at the structural scale is the low laminate strength which is caused by: the low fibre strength, the poor fibre/matrix interface and the low fibre volume fraction. The fibre strength properties can potentially be improved during fibre cultivation and the manufacturing process using different techniques to preserve the fibre properties as they are deconstructed to elemental fibres or to improve the yarn properties as they are reconstituted. However, the focus in these processes must switch from attempts to improve the stiffness to explicitly controlling the strength and the strain to failure properties. The fibre/matrix interface has the potential to be improved with the development of new resins that provide a better compatibility with the hydrophilic fibres or fibre surface treatments, with the potential that these are reliant on chemicals or processes where the sustainable benefits of flax fibres might be partially lost or perhaps even entirely removed. The fibre volume fraction can be increased with adapted manufacturing techniques but this has a limit as the irregular shape of flax fibres ensures that the highest fibre content achievable will always be lower than E-glass.

More research should be conducted on natural composite reinforced laminates before they can be safely considered for structural applications, especially at scales above the fibre. The structural behaviour of the material needs to be investigated with many more tests at the structural scale. The tensile transverse and compressive properties need to be investigated including their variability. Realistic material properties, likely to be reproducible by industry are required. Finally, the failure envelope used for this work for the flax structures is defined with the available knowledge but needs to be further investigated and represents a limitation of the paper. The applicability of the World Wide Failure Exercise criteria to natural fibre composites must be validated with experimental data and mechanical properties obtained with realistic manufacturing techniques.

\section{Conclusion}

A number of studies in the current literature compare the mechanical properties of flax fibres with E-glass and conclude that since both fibres have equivalent properties that flax can be used for structural applications. However, the literature also shows that when composite laminates are manufactured from both materials that flax properties are lower than E-glass, especially the strength properties. Currently limited tests or modelling are performed at the structural scale to determine 
whether flax is capable of replacing E-glass, which is especially important due to the increasing literature showing that these materials behave differently. Therefore a reliability assessment is performed, with material properties selected based on the literature, comparing an E-glass stiffened structure taken from the marine industry with equivalents produced from flax. It is shown that the safety of flax fibre reinforced structures is equivalent to E-glass when the flax structure is increased to 2.4 times the mass of E-glass, when using the mean properties from the literature. However, they are not a feasible replacement for volume constrained situations. The study is optimistic as the material properties considered here are for all manufacturing processes, to ensure that there is enough data, but when simulations using only the resin infusion properties for flax are considered the probabilities of failure increase. Recommendations are therefore that:

- Flax and E-glass structures are not equivalent, even though similar fibre properties are reported.

- $\quad$ Flax is widely studied in the literature, especially at the fibre scale, but this literature does not allow determination of the feasibility of flax materials for structural applications.

- The manufacturing processes considered in the literature are often the most expensive and these are unlikely to be used in the structural applications where flax might replace standard composites.

Based on these recommendations further investigations should be conducted before flax fibre reinforced composites can be safely considered for structural applications. Future research should focus on:

- a better characterisation of the transverse and compressive properties of flax fibre laminates;

- improvements to the manufacturing techniques likely to be used in structural applications, in particular to increase the fibre volume fraction and provide better fibre/matrix interfaces;

- a validation of the World Wide Failure Exercise for natural fibre reinforced composites;

- confirming the findings in this paper with investigations on a wider range of structures and structural scale experiments. 


\section{Acknowledgments}

The authors would like to thank the Lloyd's Register Foundation (LRF) for their financial support and Dr. James Blake for his kind support and comments.

\section{Data availability}

The data required to reproduce these findings are available to download from http://dx.doi.org/10.17632/tbrfwn7wsf.1

\section{References}

[1] Baley, C. and Bourmaud, A., "Average tensile properties of French elementary flax fibers," Materials Letters, vol. 122, pp. 159-161, 2014.

[2] Baley, C., "Analysis of the flax fibres tensile behaviour and analysis of the tensile stiffness increase," Composites Part A: Applied science and manufacturing, vol. 33, pp. 939-948, 2002.

[3] Charlet, K., Jernot, J.-P., Gomina, M., Bréard, J., Morvan, C. and Baley, C., "Influence of an Agatha flax fibre location in a stem on its mechanical, chemical and morphological properties," Composites Science and Technology, vol. 69, pp. 1399-1403, 2009.

[4] Pil, L., Bensadoun, F., Pariset, J. and Verpoest, I., "Why are designers fascinated by flax and hemp fibre composites?," Composites: Part A, vol. 83, pp. 193-205, 2016.

[5] Scida, D., Bourmaud, A. and Baley, C., "Influence of the scattering of flax fibres properties on flax/epoxy woven ply stiffness," Materials and Design, vol. 2017, pp. 136-145, 2017.

[6] Lefeuvre, A., Boumaud, A., Morvan, C. and Baley, C., "Tensile properties of elementary fibres of flax and glass: Analysis of reproducibility and scattering," Materials Letters, vol. 130, pp. 289-291, 2014.

[7] Blanchard, J.M.F.A., Sobey, A.J. and Blake, J.I.R. , "Multi-scale investigation into the mechanical behaviour of flax in yarn, cloth and laminate form," Composites Part $B$, vol. 84, pp. 228-235, 2016.

[8] Torres, J.P., Vandi, L.-J., Veidt, M. and Heitzmann, M.T., "The mechanical properties of natural fibre composite laminates: A statistical study," Composites: Part A, vol. 98, pp. 99-104, 2017.

[9] Liang, S., Gning, P.-B. and Guillaumat, L., "Quasi-static behaviour and damage assessment of flax/epoxy composites," Materials and Design, vol. 67, pp. 344-353, 2015.

[10] Mehmood, S. and Madsen, B., "Properties and performance of flax yarn/thermoplastic polyester composites," Journal of Reinforced Plastics and Composites, vol. 31, pp. 1746-1757, 2012.

[11] Bodros, E., Pillin, I., Montrelay, N. and Baley, C., "Could biopolymers reinforced by randomly scattered flax fibre be used in structural applications ?," Composites Science and Technology, vol. 67, pp. 462-470, 2007.

[12] Meredith, J., Coles, S.R., Powe, R., Collings, E., Cozien-Cazuc, S., Weager, B., Müssig, J. and Kirwan, K., "On the static and dynamic properties of flax and Cordenka epoxy composites," Composites Science and Technology, vol. 80, pp. 31-38, 2013.

[13] Shah, D.U., Schubel, P.J. and Clifford, M.J., "Can flax replace E-glass in structural composites? A small wind turbine blade case study," Composites: Part B , vol. 52, pp. 172-181, 2013. 
[14] Blanchard, J.M.F.A., Mutlu, U., Sobey, A.J. and Blake, J.I.R., "Modelling the different mechanical response and increased stresses exhibited by structures made from natural fibre composites," Composite Structures, 2019, In press .

[15] Bambach, M.R. , "Compression strength of natural fibre composite plates and sections of flax, jute and hemp," Thin-Walled Structures, vol. 119, pp. 103-113, 2017.

[16] Bambach, M.R., "Geometric optimisation and compression design of natural fibre composite structural channel sections," Composite Structures, vol. 185, pp. 549-560, 2018.

[17] Van de Weyenberg, I., Chi Truong, T., Vangrimde, B. and Verpoest, I., "Improving the properties of UD flax fibre reinforced composites by applying an alkaline fibre treatment," Composites Part A: applied science and manufacturing, vol. 37, pp. 1368-1376, 2006.

[18] Acera Fernández, J., Le Moigne, N., Caro-Bretelle, A.S., El Hage, R., Le Duc, A., Lozachmeur, M., Bono, P., and Bergeret, A., "Role of flax cell wall components on the microstructure and transverse mechanical behaviour of flax fabrics reinforced epoxy biocomposites," Industrial Crops and Products, vol. 85, pp. 93-108, 2016.

[19] Shah, D.U., "Developing plant fibre composites for structural applications by optimising composite parameters: a critical review," Journal of Materials Science, vol. 48, pp. 6083-6107, 2013.

[20] Coroller, G., Lefeuvre, A., Le Duigou, A., Bourmaud, A., Ausias, G., Gaudry, T. and Baley, C. , "Effect of flax fibres individualisation on tensile failure of flax/epoxy unidirectional composite," Composites: Part A, vol. 51, pp. 62-70, 2013.

[21] Koh, R. and Madsen, B., "Strength Failure Criteria Analysis for a Flax Fibre Reinforced Composite," Mechanics of Materials, vol. 124, pp. 26-32, 2018.

[22] Masseteau, B., Michaud, F., Irle, M., Roy, A. and Alise, G., "An evaluation of the effects of moisture content on the modulus of elasticity of a unidirectional flax fiber composite," Composites: Part A, vol. 60, pp. 32-37, 2014.

[23] Lebrun, G., Couture, A. and Laperriere, L., "Tensile and impregnation behavior of unidirectional hemp/paper/epoxy and flax/paper/epoxy composites," Composite Structures, vol. 103, pp. 151-160, 2013.

[24] Charlet, K., Baley, C., Morvan, C., Jernot, J.-P., Gomina, M. and Breard, J., “Characterstics of Hermes flax fibres as a function of their location in the stem and properties of the derived unidirectional composites," Composites Part A: applied science and manufacturing, vol. 38, pp. 1912-1921, 2007.

[25] Hepworth, D.G., Bruce, D.M., Vincent, J.F.V. and Jeronimidis, G., "The manufacture and mechanical testing of thermosetting natural fibre composites," Journal of Materials Science, vol. 35, pp. 293-298, 2000.

[26] Baley, C., Le Duigou, A., Bourmaud, A. and Davies, P. , "Influence of drying on the mechanical behaviour of flax fibres and their unidirectional composites," Composites: Part A, vol. 43, pp. 1226-1233, 2012.

[27] Lefeuvre, A., Bourmaud, A. and Baley, C., "Optimization of the mechanical performance of UD flax/epoxy composites by selection of fibres along the stem," Composites: Part $A$, vol. 77, pp. 204-208, 2015. 
[28] Martin, N., Davies, P. and Baley, C., "Comparison of the properties of scutched flax and flax tow for composite material reinforcement," Industrial Crops and Products, vol. 61, pp. 284292, 2014.

[29] Mahboob, Z., Chemisky, Y., Meraghni, F. and Bougherara, H., "Mesoscale modelling of tensile response and damage evolution in natural fibre reinforced laminates," Composites Part $B$, vol. 119, pp. 168-183, 2017.

[30] Mahboob, Z., El Sawi, I., Zdero, R., Fawaz, Z. and Bougherara, H., "Tensile and compressive damaged response in Flax fibre reinforced epoxy composites," Composites: Part $A$, vol. 92, pp. 118-133, 2017.

[31] Scida, D., Assarar, M., Poilane, C. and Ayad, R., "Influence of hygrothermal ageing on the damage mechanisms of flax-fibre reinforced epoxy composite," Composites: Part $B$, vol. 48, pp. 51-58, 2013.

[32] Li, Y., Li, Q. and Ma, H., "The voids formation mechanisms and their effects on the mechanical properties of flax fiber reinforced epoxy composites," Composites: Part A, vol. 72, pp. 40-48, 2015.

[33] Poilane, C., Cherif, Z.E., Richard, F., Vivet, A., Ben Doudou, B. and Chen, J., "Polymer reinforced by flax fibres as a viscoelastoplastic material," Composite Structures, vol. 112, pp. 100-112, 2014.

[34] Berges, M., Léger, R., Placet, V., Person, V., Corn, S., Gabrion, X., Rousseau, J., Ramasso, E., Lenny, P., and Fontaine, S., "Influence of moisture uptake on the static, cyclic and dynamic behaviour of unidirectional flax fibre-reinforced epoxy laminates," Composites: Part $A$, vol. 88, pp. 165-177, 2016.

[35] Cherif, Z.E., Poilane, C., Vivet, A., Ben Doudou, B. and Chen, J., "About optimal architecture of plant fibre textile composite for mechanical and sorption properties," Composite Structures, vol. 140, pp. 240-251, 2016.

[36] Lamy, B. and Pomel, C., "Influence of fiber defects on the stiffness properties of flax fibersepoxy composite materials," Journal of materials science letters, vol. 21, pp. 1211-1213, 2002.

[37] Van Vuure, A.W., Baets, J., Wouters, K. and Hendrickx, K., "Compressive properties of natural fibre composites," Materials Letters, vol. 149, pp. 138-140, 2015.

[38] Shah, D.U., Schubel, P.J., Clifford, M.J. and Licence, P., "Mechanical Property Characterization of Aligned Plant Yarn Reinforced Thermoset Matrix Composites Manufactured via Vacuum Infusion," Polymer-Plastics Technology and Engineering , vol. 53, pp. 239-253, 2014.

[39] Campana, C., Leger, R., Sonnier, R., Ferry, L. and lenny, P., "Effect of post curing temperature on mechanical properties of flax fiber reinforced epoxy composite," Composites: Part $A$, vol. 107, pp. 171-179, 2018.

[40] Van de Weyenberg, I., Ivens, J., De Coster, A., Kino, B., Baetens, E. and Verpoest, I., "Influence of processing and chemical treatment of flax fibres on their composites," Composites Science and Technology, vol. 63, pp. 1241-1246, 2003.

[41] Baets, J., Plastria, D., Ivens, J. and Verpoest, I. , "Determination of the optimal flax fibre preparation for use in unidirectional flax-epoxy composites," Journal of reinforced plastics and composites, vol. 0, no. 0, pp. 1-10, 2013. 
[42] Kersani, M., Lomov, S. V., Van Vuure, A.W., Bouabdallah, A. and Verpoest, I., "Damage in flax/epoxy quasi-unidirectional woven laminates under quasi-static tension," Journal of composite materials, vol. 49, no. 4, pp. 403-413, 2015.

[43] Oksman, K., "High Quality Flax Fibre Composites Manufactured by the Resin Transfer Moulding Process," Journal of Reinforced Plastics and Composites, vol. 20, no. 7, pp. 621-627, 2001.

[44] Oksman, K., Wallström, L., Berglund, L.A., "Morphology and mechanical properties of unidirectional sisal- epoxy composites," Journal of Applied Polymer Science, vol. 84, no. 13, pp. 2358-65, 2002.

[45] Duc, F., Bourban, P.E., Plummer, C.J.G. and Manson, J.-A.E., "Damping of thermoset and thermoplastic flax fibre composites," Composites: Part A, vol. 64, pp. 115-123, 2014.

[46] Bensadoun, F., Vallons, K.A.M., Lessard, L.B., Verpoest, I. and Van Vuure, A.W., "Fatigue behaviour assessment of flax-epoxy composites," Composites: Part A, vol. 82, pp. 253-266, 2016.

[47] Habibi, M., Laperriere, L., Lebrun, G. and Toubal, L., "Combining short flax fiber mats and unidirectional flax yarns for composite applications: Effect of short flax fibers on biaxial mechanical properties and damage behaviour," Composites Part B, vol. 123, pp. 165-178, 2017.

[48] Monti, A., El Mahi, A., Jendli, Z. and Guillaumat, L., "Mechanical behaviour and damage mechanisms analysis of a flax-fibre reinforced composite by acoustic emission," Composites: Part A, vol. 90, pp. 100-110, 2016.

[49] Castegnaro, S., Gomiero, C., Battisti, C., Poli, M., Basile, M., Barucco, P., Pizzarello, U., Quaresimin, M. and Lazzareto, A., "A bio-composite racing sailboat: Materials selection, design, manufacturing and sailing," Ocean Engineering, vol. 133, pp. 142-150, 2017.

[50] Goutianos, S., Peijis, T., Nystrom, B. and Skrifvars, M., "Development of Flax Fibre based Textile Reinforcements for Composite Applications," Applied Composite Materials, vol. 13, pp. 199-215, 2006.

[51] Xue, D. and Hu, H. , "Mechanical properties of biaxial weft-knitted flax composites," Materials and Design , vol. 46, pp. 264-269, 2013.

[52] Perremans, D., Verpoest, I., Dupont-Gillain, C. and Van Vuure, A.W., "Investigation of the tensile behavior of treated flax fibre bio-composites at ambient humidity," Composites Science and Technology, vol. 159, pp. 119-126, 2018.

[53] Dhakal, H.N., Zhang, Z.Y., Guthrie, R., MacMullen, J. and Bennett, N., "Development of flax/carbon fibre hybrid composites for enhanced properties," Carbohydrate Polymers, vol. 96, pp. 1-8, 2013.

[54] Bos, H.L., Molenveld, K., Teunissen, W., Van Wingerde, A.M. and Van Delft, D.R.V., "Compressive behaviour of unidirectional flax reinforced composites," Journal of materials science, vol. 39, pp. 2159-2168, 2004.

[55] Gning, P.B., Liang, S., Guillaumat, L. and Pui, W.J., "Influence of process and test parameters on the mechanical properties of flax/epoxy composites using response surface methodology," Journal of Materials Science, vol. 46, pp. 6801-6811, 2011. 
[56] Liang, S., Gning, P.B. and Guillaumat, L., "Properties evolution of flax/epoxy composites under fatigue loading," International Journal of fatigue, vol. 63, pp. 36-45, 2014.

[57] El Sawi, I., Fawaz, Z., Zitoune, R. and Bougherara, H., "An investigation of the damage mechanisms and fatigue life diagrams of flax fiber-reinforced polymer laminates," Journal of Materials Science, vol. 49, pp. 2338-2346, 2014.

[58] Baley, C., Kervoelen, A., Le Duigou, A., Goudenhooft, C. and Bourmaud, A., "Is the low shear modulus of flax fibres an advantage for polymer reinforcement?," Materials Letters, vol. 185, pp. 534-536, 2016.

[59] Bensadoun, F., Verpoest, I., Baets, J., Mussig, J., Graupner, N., Davies, P., Gomina, M., Kervoelen, A. and Baley, C., "Impregnated fibre bundle test for natural fibres used in composites," Journal of Reinforced Plastics and Composites, vol. 36, no. 13, pp. 942-957, 2017.

[60] Assarar, M., Scida, D., El Mahi, A., Poilane, C. and Ayad, R., "Influence of water ageing on mechanical properties and damage events of two reinforced composite materials: Flax-fibres and glass-fibres," Materials and Design , vol. 32, pp. 788-795, 2011.

[61] El-Hafidi, A., Gning, P.B., Piezel, B., Belaid, M. and Fontaine, S., "Determination of dynamic properties of flax fibres reinforced laminate using vibration measurements," Polymer testing , vol. 57, pp. 219-225, 2017.

[62] Cadu, T., Berges, M., Sicot, O., Person, V., Piezel, B., Van Schoors, L., Placet, V., Corn, S., Léger, R., Divet, L., lenny, P. and Fontaine, S.,, "What are the key parameters to produce a highgrade bio-based composite? Application to flax/epoxy UD laminates produced by thermocompression," Composites Part B: Engineering, vol. 150, pp. 36-46, 2018.

[63] Ravandi, M., Teo, W.S., Tran, L.Q.N., Yong, M.S. and Tay, T.E., "The effects of through-thethickness stitching on the Mode I interlaminar fracture toughness of flax/epoxy composite laminates," Materials and Design , vol. 109, pp. 659-669, 2016.

[64] George, J., Ivens, J. and Verpoest, I., "Mechanical properties of flax fibre reinforced epoxy composites," Die Angewandte Makromolekulare Chemie, vol. 272, no. 4747, pp. 41-45, 1999.

[65] Li, Y. and Xue, B., "Hydrothermal ageing mechanisms of unidirectional flax fabric reinforced epoxy composites," Polymer Degradation and Stability, vol. 126, pp. 144-158, 2016.

[66] Pucci, M.F., Liotier, P.-J., Seveno, D., Fuentes, C., Van vuure, A. and Drapier, S., "Wetting and swelling property modifications of elementary flax fibres and their effects on the Liquid Composite Molding process," Composites: Part A, vol. 97, pp. 31-40, 2017.

[67] Flynn, J., Amiri, A. and Ulven, C., "Hybridized carbon and flax fiber composites for tailored performance," Materials and Design , vol. 102, pp. 21-29, 2016.

[68] Gassan, J., "A study of fibre and interface parameters affecting the fatigue behaviour of natural fibre composites," Composites Part A: applied science and manufacturing, vol. 33, pp. 369-374, 2002.

[69] Manders, P.W. and Bader, M.G., "The strength of hybrid glass/carbon fibre composites, Part 1 Failure strain enhancement and failure mode," Journal of materials science, vol. 16, pp. 22332245, 1981.

[70] Varna, J., Joffe, R., Akshantala, N.V. and Talreja, R., "Damage in composite laminates with offaxis plies," Composites Science and Technology, vol. 59, no. 14, pp. 2139-2147, 1999. 
[71] Quaresimin, M. and Carraro, P.A., "Damage initiation and evolution in glass/epoxy tubes subjected to combined tension-torsion fatigue loading," International Journal of Fatigue, vol. 63, pp. 25-35, 2014.

[72] Quaresimin, M. and Carraro, P.A., "On the investigation of the biaxial fatigue behaviour of unidirectional composites," Composites: Part B, vol. 54, pp. 200-208, 2013.

[73] Kishore, R.A., Tiwari, R., Dvivedi, A. and Singh, I., "Taguchi analysis of the residual tensile strength after drilling in glass fiber reinforced epoxy composites," Materials \& Design, vol. 30, no. 6, pp. 2186-2190, 2009.

[74] Mishra, R., Malik, J., Singh, I. and Davim, J. P., "Neural network approach for estimating the residual tensile strength after drilling in uni-directional glass fiber reinforced plastic laminates," Materials \& Design, vol. 31, no. 6, pp. 2790-2795, 2010.

[75] Rakesh, P.K., Singh, I. and Kumar, D., "Failure prediction in glass fiber reinforced plastics laminates with drilled hole under uni-axial loading," Materials \& Design, vol. 31, no. 6, pp. 3002-3007, 2010.

[76] Cheon, S.S., Lim, T.S. and Lee, D.G., "Impact energy absorption characteristics of glass fiber hybrid composites," Composite Structures, vol. 46, no. 3, pp. 267-278, 1999.

[77] Soden, P.D., Hinton, M.J. and Kaddoura, A.S. , "Lamina properties, lay-up configurations and loading conditions for a range of fibre-reinforced composite laminates," Composites Science and Technology, vol. 58, no. 7, pp. 1011-1022, 1998.

[78] Kaddour, A.S. and Hinton, M.J., "Input data for test cases used in benchmarking triaxial failure theories of composites," Journal of Composite Materials, vol. 46, no. 19-20, pp. 2295-2312, 2012.

[79] Zhu, Y., Qin, Y., Qi, S., Xu, H., Liu D. and Yan, C., "Variable Angle Tow reinforcement design for locally reinforcing an open-hole composite plate," Composite Structures, vol. 202, pp. 162$169,2018$.

[80] Perillo, G., Vedivik, N.P. and Echtermeyer, A.T., "Damage development in stich bonded GFRP composite plates under low velocity impact: Experimental and numerical results," Journal of Composite Materials, vol. 49, no. 5, pp. 601-615, 2015.

[81] Sánchez-Heres, L.F., Ringsberg, J.W. and Johnson, E., "Influence of mechanical and probabilistic models on the reliability estimates of fibre-reinforced cross-ply laminates," Structural Safety, vol. 51, pp. 35-46, 2014.

[82] Andersons, J., Joffe, R. and Sparnins, E. , "Statistical model of the transverse ply cracking in cross-ply laminates by strength and fracture toughness based failure criteria," Engineering Fracture Mechanics, vol. 75, no. 9, pp. 2651-2665, 2008.

[83] Bledzki, A.K., Kessler, A., Rikards, R. and Chate, A. , "Determination of elastic constants of glass/epoxy unidirectional laminates by the vibration testing of plates," Composites Science and Technology, vol. 59, no. 13, pp. 2015-2024, 1999.

[84] Singh, I. and Bhatnagar, N., "Drilling-induced damage in uni-directional glass fiber reinforced plastic (UD-GFRP) composite laminates," The International Journal of Advanced Manufacturing Technology, vol. 27, pp. 877-882, 2006. 
[85] Albanesi, A., Roman, N., Bre, F. and Fachinotti, V., "A metamodel-based optimization approach to reduce the weight of composite laminated wind turbine blades," Composite Structures, vol. 194, pp. 345-356, 2018.

[86] Ribeiro, F., Sena-Cruz, J., Branco, F.G. and Júlio, E., "Hybrid effect and pseudo-ductile behaviour of unidirectional interlayer hybrid FRP composites for civil engineering applications," Construction and Building Materials, vol. 171, pp. 871-890, 2018.

[87] Masoumi, A., Shojaeefard, M.H. and Najibi, A. , "Comparison of steel, aluminium and composite bonnet in terms of pedestrian head impact," Safety Science, vol. 49, pp. 13711380, 2011.

[88] Wacker, G., Bledzki, A.K. and Chate, A., "Effect of interphase on the transverse Young's modulus of glass/epoxy composites," Composites Part A, vol. 29, no. A, pp. 619-626, 1998.

[89] Barbero, E.J., Cosso, F.A., Roman, R. and Weadon, T.L. , "Determination of material parameters for Abaqus progressive damage analysis of E-glass epoxy laminates," Composites: Part B, vol. 46, pp. 211-220, 2013.

[90] Hsieh, T.H., Kinloch, A.J., Masania, K., Sohn Lee, J., Taylor, A.C. and Sprenger, S., "The toughness of epoxy polymers and fibre composites modified with rubber microparticles and silica nanoparticles," Journal of Materials Science, vol. 45, no. 5, pp. 1193-1210, 2010.

[91] Tewari, U.S., Harsha, A.P., Häger, A.M. and Friedrich, K., "Solid particle erosion of carbon fibre- and glass fibre-epoxy composites," Composites Science and technology, vol. 63, no. 34, pp. 549-557, 2003.

[92] Wisnom, M.R. and Atkinson, J.W., "Reduction in tensile and flexural strength of unidirectional glass fibre-epoxy with increasing speciment size," Composite Structures, vol. 38, no. 1-4, pp. 405-411, 1997.

[93] Harsha, A.P. and Jha, S.K., "Erosive wear studies of epoxy-based composites at normal incidence," Wear, vol. 265, no. 7-8, pp. 1129-1135, 2008.

[94] Kenane, M., Bennedakhene, S. and Azari, A., "Fracture and fatigue study of unidirectional glass/epoxy laminate under different mode of loading," Fatigue \& Fracture of Engineering Materials \& Structures, vol. 33, no. 5, pp. 284-293, 2010.

[95] Kennedy, C.R., O Bradaigh, C.M. and Leen, S.B., "A multiaxial fatigue damage model for fibre reinforced polymer composites," Composite Structures, vol. 106, pp. 201-210, 2013.

[96] Ou, Y. and Zhu, D. , "Tensile behavior of glass fiber reinforced composite at different strain rates and temperatures," Construction and Building Materials, vol. 96, pp. 648-656, 2015.

[97] Lekou, D.J. and Philippidis, T.P., "Mechanical property variability in FRP laminates and its effect on failure prediction," Composites Part B: Engineering , vol. 39, pp. 1247-1256, 2008.

[98] Phillips, S., Baets, J., Lessard, L., Hubert, P. and Verpoest, I., "Characterization of flax/epoxy prepregs before and after cure," Journal of Reinforced Plastics \& Composites, vol. 0, no. 0, pp. 1-9, 2012.

[99] Yang, N., Das, P.K., Blake, J.I.R., Sobey, A.J. and Shenoi, R.A., "The application of reliability methods in the design of tophat stiffened composite panels under in-plane loading," Marine Structures, vol. 32, pp. 68-83, 2013. 
[100] Madsen, B. and Lilholt, H., "Physical and mechanical properties of unidirectional plant fibre composites-an evaluation of the influence of porosity," Composites Science and Technology, vol. 63, pp. 1265-1272, 2003.

[101] Charlet, K., Jernot, J.-P., Gomina, M., Bizet, L. and Bréard, J., "Mechanical Properties of Flax Fibers and of the Derived Unidirectional Composites," Journal of Composite Materials, vol. 44, pp. 2887-2896, 2010.

[102] Shah, D.U., Nag, R.K. and Clifford, M.J., "Why do we observe significant differences between measured and 'back-calculated' properties of natural fibres?," Cellulose, vol. 23, no. 3, pp. 1481-1490, 2016.

[103] Moothoo, J., Allaoui, S., Ouagne, P. and Soulat, D., , "A study of the tensile behaviour of flax tows and their potential for composite processing," Materials and Design, vol. 55, pp. 764772, 2014.

[104] Sobey, A.J., Blake, J.I.R. and Shenoi, R.A., "Monte Carlo reliability analysis of tophat stiffened composite plate structures under out of plane loading," Reliability Engineering \& System Safety, vol. 110, pp. 41-49, 2013.

[105] Jeong, H.K. and Shenoi, R.A. , "Probabilistic strength analysis of rectangular FRP plates using Monte Carlo simulation," Computers \& Structures, vol. 76, pp. 219-235, 2000.

[106] Liu, K.- L. and Tsai, S.T., "A progressive quadratic failure criterion for a laminate," Composites Science and Technology, vol. 58, pp. 1023-1032, 1998.

[107] Zinoviev, P.A., Grigoriev, S.V., Lebedeva, O.V. and Tairova, L.P., "The strength of multilayered composites under a plane-stress state," Composites Science and Technology, vol. 58, pp. 1209-1223, 1998.

[108] Palmer, A., "10-6 and all that: what do failure probabilities mean?," Journal of Pipeline Engineering, vol. 12, no. 4, pp. 269-271, 2012.

[109] G. Vedeler, Grillage Beams in Ships and similar Structures, Oslo : Grondhal \& Son, 1945.

[110] Bourmaud, A., Gibaud, M., Lefeuvre, A., Morvan, C. and Baley, C. , "Influence of the morphology characters of the stem on the lodging resistance of Marylin flax," Industrial Crops and Products, vol. 66, no. 1, pp. 27-37, 2015.

[111] Ehresmann, M., Amiri, A. and Ulven, C. , "The effect of different variables on in-plane radial permeability of natural fiber mats," Journal of Reinforced Plastics \& Composites, vol. 0, pp. 111, 2016.

[112] Amiri, A., Triplett, Z., Moreira, A., Brezinka, N., Alcock, M. and Ulven, C. A., "Standard density measurement method development for flax fiber," Industrial Crops and Products, vol. 96, pp. 196-202, 2017.

[113] COMMITTEE IV.1., "Design Principles and Criteria," in Proceedings of the 13th International Ship and Offshore Structures Congress, Trondheim, Norway, 1997.

[114] Shah, D.U., "Damage in biocomposites: Stiffness evolution of aligned plant fibre composites during monotonic and cyclic fatigue loading," Composites: Part A, vol. 83, pp. 160-168, 2016. 